\title{
Psychological peritraumatic risk factors for post-traumatic stress disorder in children and
}

adolescents: A meta-analytic review

Authors:

Jessica Memarzia $^{1,2}$, Jack Walker ${ }^{2}$, Richard Meiser-Stedman $^{2}$

${ }^{1}$ Peterborough Integrated Neurodevelopmental Service, Child and Adolescent Mental Health

Service, Cambridgeshire and Peterborough Foundation NHS Trust, Winchester Place, 80 Thorpe

Road, Peterborough, PE3 6AP

${ }^{2}$ Department of Clinical Psychology and Psychological Therapies, Norwich Medical School, University of East Anglia, NR4 7TJ

Corresponding author: Dr Jessica Memarzia, Peterborough Integrated Neurodevelopmental Service, Child and Adolescent Mental Health Service, Cambridgeshire and Peterborough Foundation NHS Trust, Winchester Place, 80 Thorpe Road, Peterborough, PE3 6AP. Email: j.memarzia@ gmail.com 


\section{Introduction}

Our understanding, conceptualisation, and treatment strategies for post-trauma psychopathological reactions has evolved greatly over the past two decades, with particular development more recently in our insight into post-trauma reactions in children and adolescents. Post-traumatic stress disorder (PTSD) is defined by DSM-5 as occurring following the experience or witnessing of an event(s) that involved actual or threatened death, serious injury, or sexual violence. Following this experience, an individual experiences (one of five of the following) recurrent, involuntary and intrusive recollections, nightmares, dissociative reactions (e.g. flashbacks), significant distress or physiological responses after exposure to triggers or reminders of the event, plus: persistent avoidance of reminders or triggers related to the trauma (thoughts or feelings, or people, places, activities); negative alterations in cognitions and mood (dissociative amnesia, negative beliefs about oneself or the world, blame of self or others, negative traumarelated emotions, diminished interest in activities, sense of detachments from others, or restricted affect), and alterations in arousal and reactivity (irritability, self-destructive or reckless behaviour, hypervigilance, exaggerated startle response, difficulty concentrating, or sleep disturbance); all leading to a significant symptom-related distress or impairment in functioning. The earlier DSM-IV criteria did not include the negative alterations in cognitions and mood symptom cluster, and instead included many of its symptoms in an avoidance and numbing cluster.

Clinically, the accurate identification of key psychological processes implicated in the development of PTSD, soon after trauma, is vital in recognising which children may go on to develop chronic symptoms of PTSD. While a majority of children and young people will experience some kind of traumatic event in their young lives (an estimated 68\%; Copeland, Keeler, Angold, \& Costello, 2007), and acute symptoms of post-traumatic stress are common, only an estimated $8-16 \%$ of individuals develop chronic symptoms of PTSD (Alisic, et al., 2014; Bryant, Mayou, Wiggs, Ehlers, \& Stores, 2004; Copeland, et al., 2007; Costello, Erkanli, Fairbank, \& Angold, 2002; Kilpatrick, et al., 2013; Ogle, Rubin, Berntsen, \& Siegler, 2013). There have been substantial 
research efforts to unpick the role of different psychosocial, trauma-related, and psychological factors, in order to identify key risk factors for the development of PTSD. However, evidence and conclusions drawn have been variable, and there have been few reviews that have summated this research.

Research efforts have explored pre-trauma factors (such as psychosocial and demographic participant characteristics), trauma-related factors (including trauma type, injury severity and peritrauma experiences), and post-trauma factors (such as cognitive processing of the trauma, social, and parental support). Evidence pertaining to pre-trauma and demographic factors as risk factors or predictors of PTSD development following trauma has been particularly mixed. For example, both younger age and older age have been suggested to be associated with increased likelihood of presenting with symptoms of PTSD (Cox, Kenardy, \& Hendrikz, 2008; Foy, Madvig, Pynoos, \& Camilleri, 1996; Scheeringa, Wright, Hunt, \& Zeanah, 2006; Trickey, Siddaway, Meiser-Stedman, Serpell, \& Field, 2012). Following the meta-analysis of available evidence of pre-trauma risk factors (e.g. socio-economic status, gender) for PTSD in children and adolescents, it has been concluded that the predictive power of pre-trauma variables is small compared to trauma-related and post-trauma factors (Cox, et al., 2008; Trickey, et al., 2012).

Trauma-related factors, such as degree of exposure to aspects of events, whether death was caused by the trauma, and severity of injury to the child, have often been conceptualised as factors which increase the likelihood of PTSD (Pine \& Cohen, 2002). While Trickey and colleagues (2012) found that the relationship between trauma severity and PTSD comprised a medium to large effect, there was considerable heterogeneity in this relationship. Subjective peritraumatic experiences have been previously been conceptualised as core factors in the development of PTSD. DSM-IV criteria for PTSD (Diagnostic and Statistical Manual for Mental Disorders $4^{\text {th }}$ Edition; American Psychiatric Association, 2000) stipulated the experience of fear, horror, helplessness and/or perceived life threat as necessary characteristics of a trauma experience for a diagnosis of PTSD. However, these trauma characteristics are no longer noted as necessary for diagnosis in DSM-5 
(American Psychiatric Association, 2013; Friedman, Resick, Bryant \& Brewin, 2011). The strength of the effect of the relationship between peritraumatic subjective experience and PTSD in children has been reported to be moderate to large (population estimate of effect size $r=0.36$ for perceived life threat), however, few studies were found to report on this relationship in the most recent review of predictors of PTSD in children and adolescents (Trickey, et al., 2012).

A further peritraumatic experience which has received attention in PTSD research is dissociation. This phenomenon refers to when an individual enters a state of emotional numbness, derealisation, or depersonalisation during or shortly after a trauma, and is thought to be a risk factor for developing PTSD (Breh \& Seidler, 2007). It has been conceptualised as a neurophysiological attempt to conserve resources during heightened threat by shutting down responsiveness, which has unfortunate detrimental consequences (Saxe, et al., 2005). Dissociation at the time of the trauma is thought to increase feelings of helplessness and disrupt the normal processing of an event. As a result, memories of the event are thought to be stored in a fragmented and poorly integrated manner, leading to the increased likelihood of flashbacks and intrusive thoughts (Ehlers \& Clark, 2000). Dissociation - both during and after a trauma - has mostly been investigated in the context of the DSM-IV acute stress disorder (ASD) diagnosis. However, a review of findings related to dissociation and PTSD across the lifespan concluded that it was not an optimal predictor of PTSD (Bryant, 2007).

Cognitive models of PTSD in children and adults elucidate how, in addition to dissociation, subjective peritraumatic experiences such as perceived threat, data-driven processing (feeling muddled or confused), feelings of panic and fear play a role in the development of PTSD. These theoretical models outline how a number of cognitive processes including how trauma memories are formed at the time of the trauma, how the trauma event is appraised, and the use of maladaptive thinking styles post-trauma, lead to the development and maintenance of PTSD symptoms (Brewin, Dalgleish, \& Joseph, 1996; Ehlers \& Clark, 2000; Foa, Steketee, \& Rothbaum, 1989). These models implicate the nature of trauma memories and the cognitive processes by which these memories are 
formed as being key in the development of PTSD. Brewin et al. (1996) formulated a dual representation model based on cognitive neuroscience perspectives, suggesting how memories of a trauma are processed and stored differently to non-trauma memories. Within this model, the development and continuation of PTSD symptoms arises due to an inability to fully process and integrate highly sensory and verbal memories representing the individual's appraisals, emotional and physiological reactions to the trauma. Poor social support, any prior or ongoing trauma, aversive secondary emotions, the severity of the trauma, and prior psychopathology are all deemed as risk factors to the inhibition of adaptive processing of the trauma memories and leading to ongoing PTSD.

Similarly, Ehlers and Clark (2000) postulate a conceptualisation of PTSD which depicts two pertinent cognitive factors in the development of PTSD; the nature of the trauma memory and the appraisals developed related to the trauma experienced. In cases where PTSD is developed, peritraumatic cognitive processes, including data-driven processing (the focus on sensory experience reducing understanding of what was going on in the situation), results in the development of trauma memories lacking contextual detail, but with strong conditioned associations. These features lead to the memory easily being involuntarily brought into consciousness with a poor sense of it being an event which occurred in the past, and other contextual information. If overly negative appraisals of the event are also developed, trauma memories are accompanied by negative intrusions and distressing emotional responses, for example guilt, self-blame or anger. A range of cognitive and behavioural responses to this highly distressing re-experiencing then maintain the PTSD, for example rumination. The authors of both these models of PTSD argue that these peri- and post-traumatic cognitive factors are equally important as preand peri-traumatic experiences or other, such as psychosocial, factors as predictors of the development of PTSD. They argue that the prevention of adaptive processing of trauma memories leads to increased risk of individuals suffering from more chronic PTSD. Both these cognitive models of PTSD were developed in relation to PTSD in adults, however, a review of research and 
understanding of PTSD in children and adolescents found that the concepts described by each model map onto the presentation of PTSD in children and adolescents, supporting the applicability of these models across the life span (Meiser-Stedman, 2002).

\section{Aim of the current review}

Trickey and colleagues' (2012) meta-analytic review of risk factors for PTSD in children and adolescents found that the vast majority of studies explored the role of pre-trauma and demographic factors, and post-trauma factors; only nine effect sizes related to peritraumatic factors were drawn from 62 identified studies of PTSD predictors in children and adolescents. This review therefore aimed to conduct a comprehensive search and collation of empirical research shedding light on the role of peritraumatic psychological processes in the development of PTSD in children and adolescents. This aimed to provide an update and development of previous reviews, with a specific focus on peritraumatic risk factors. Allowing comparison between different peritraumatic psychological processes, and identifying which have stronger or weaker relationships with PTSD symptoms, will have important implications in developing the theoretical understanding of the disorder in this population, and directing future research and clinical practice. Previous reviews suggest that there have been relatively few studies of peritraumatic processes in children and adolescents, but these reviews did not specifically target peritraumatic psychological processes in their search terms. Cognitive theories of PTSD place certain peritraumatic processes as central in the development of PTSD, and diagnostic manuals have previously stated that a diagnosis of PTSD depends upon experiencing key thoughts and feelings during or immediately after a trauma, but these theoretical and diagnostic claims have not been formally addressed in a systematic review.

\section{Method}


This review was registered on the PROSPERO register of systematic reviews $\left(25^{\text {th }}\right.$ September 2017, CRD42017068946). An initial search of the leading psychological and medical literature databases was conducted, including PubMed (MEDLINE), PsycINFO and the National Centre for PTSD research's Published International Literature on Traumatic Stress (PILOTS) database. While the initial planned review was intended to address peritraumatic factors and PTSD in both child and adolescent and adult populations, given the size of the literature a decision was made to focus exclusively on children and adolescents. Reference sections of included studies and existing meta-analyses of predictors of PTSD were also reviewed to identify any possible relevant studies. The search dated from 1980 (when PTSD was first defined as a diagnosis in the Diagnostic and Statistical Manual of Mental Disorders, $3^{\text {rd }}$ Edition (DSM-III); American Psychiatric Association, 1980) to December 2017. The search terms were developed by reviewing other metaanalyses and review articles, and were refined for the purposes of identifying broadly applicable studies initially. The search terms were 'PTSD OR posttraumatic stress disorder OR post-traumatic stress disorder OR posttraumatic stress OR post-traumatic stress' AND 'peri-traum* OR peritraum* OR during’ AND ‘dissociat* OR fear OR helpless* OR horror OR confus* OR threat OR defeat OR perceive OR perception OR panic OR emotion* OR distress* OR data-driven OR data driven OR cognit* OR process'. Initial searches were open to all ages, and then child and adolescent studies were identified by screening within this, as some studies may have assessed adults and children and reported on the groups separately. All searches were run by searching 'full text', however, initial search results suggested that some databases may not have access to search full texts, and as risk factors, particularly peritraumatic factors, may not be mentioned in titles or abstracts, a fourth database search was run using PsycARTICLES which successfully searched article full texts.

\section{Inclusion and exclusion criteria}

To be considered for inclusion, studies had to present data on predictive or risk factors for PTSD, with clearly defined assessment of one or more psychological peritraumatic risk factor(s) in 
child and adolescent samples. Peritraumatic psychological processes were defined as a cognitive or emotional process or experience which occurred during or immediately after the trauma. Studies were required to use a measure of PTSD which has evidence demonstrating its reliability and validity (within any population, not solely the population under study) which considered the diagnostic criteria for PTSD: symptoms of intrusion, avoidance and hyperarousal. One study was included which did not use a previously validated measure of PTSD, but utilised a psychiatric interview conducted by a qualified psychiatrist based on a checklist of ICD-10 symptoms for PTSD (World Health Organisation, 1992). The assessment of PTSD in this study not being based on a validated measure with published reliability psychometrics was reflected in the study quality assessment score.

Clinical and community samples were included, as long as clinical samples did not just present data on participants with PTSD alone (a non-PTSD comparison group was required to calculate effect sizes of risk factors for PTSD). Studies were excluded if participants were recruited primarily due to a specific comorbid disorder or presentation or had a traumatic brain injury. Study methodology was considered, with studies excluded if peritraumatic factors were assessed more than three years post trauma, in line with previous reviews and evidence to suggest that reporting of peritraumatic experiences is not stable over time due to forgetting (Candel \& Merckelbach, 2004; Cox, et al., 2008). While we had initially planned to restrict this period to six months post-trauma, given the number of the studies that went outside this window we opted to instead to extend the period and undertake meta-regression of this variable. Studies were also excluded if when the trauma occurred, or the time since the trauma, were not clearly stipulated, or 'lifetime' trauma was assessed. PTSD must have been assessed one month or more post-trauma (in line with DSM-5 criteria); studies of acute stress reactions or acute stress disorder were excluded. All academic journal articles, dissertation papers, longitudinal, follow-up or cross-sectional studies were considered. Single case studies, studies presenting qualitative data alone, and clinical treatment trials were excluded. See the PRISMA (Preferred Reporting Items for Systematic Reviews and 
Meta-Analyses; Moher, Liberati, Tetzlaff \& Altman, 2009) flow diagram (Figure 1) demonstrating the study selection, exclusion, and inclusion processes.

\section{Data extraction}

A number of rules were adhered to clarify uncertainty in the data extraction process. If information was given on both lifetime and current PTSD, effect sizes for current PTSD were used. If PTSD was identified by using both continuous measures (symptom severity) and dichotomous measures (diagnosis), effect sizes from continuous measures were prioritised to avoid underestimation of effect size due to dichotomisation of data. For longitudinal studies with multiple points of assessment of PTSD, effect sizes were derived from the time point nearest to the traumatic event (as long as it was more than one month post-trauma).

\section{Grouping of peritraumatic factors}

Several studies used measures of risk factors which assessed a range of different psychological, cognitive, and emotional experiences at the time of trauma; these were variously labelled as 'peritraumatic distress', 'peritraumatic reaction', or 'A2 criteria', with one effect size reported from this overall peritraumatic experience measure. The assessment of 'A2' criteria included measures of the PTSD DSM-IV criteria of experiencing fear, horror, helplessness, or perceived life threat during or immediately after the trauma. This informed our grouping of all effect sizes measuring 'subjective threat' or 'A2' criteria; including these overall measures of peritraumatic reactions of fear, helplessness, horror, and perceived life threat.

A second group of effect sizes focussed on peritraumatic dissociation, which was measured very specifically within the studies included. A third group of effect sizes reflected the assessment of data-driven processing (feeling confused or muddled during the trauma), which again was very specifically measured within the studies included. A final group focussed on the effect sizes related to 'pure' perceived life threat, assessed specifically (mostly with a single item) and without mention of any other peritraumatic experience within the measure. 


\section{Calculating effect sizes}

Pearson's correlation coefficient, $r$, was used as the effect size in this current meta-analysis. Most studies reported this statistic in their analysis of risk factors of PTSD; for those which reported $\beta$, t-tests, ANOVAs, or odds ratios, 'r' was computed following standardised calculations for transforming effect sizes (e.g. Borenstein, Hedges, Higgins \& Rothstein, 2009). Pearson's correlation coefficient is also readily interpretable, with .1 considered a small effect, .3 a medium effect and $r=.5$ or higher a large effect (Cohen, 1988). If a study reported multiple effect sizes for one peritraumatic factor, e.g. perceived life threat to self and perceived life threat to others was assessed separately (whereas other studies assessed this within one measure and reported one effect size), r's were converted to Fisher's $\mathrm{z}$, a mean was calculated and then the $\mathrm{z}$ was transformed back to $r$ to be included in the meta-analysis (Borenstein, 2009). Where a particular peritraumatic risk factor was reported as having a non-significant effect on PTSD and no statistic for this result was provided, the effect size was assumed as being zero (Rosenthal, 1991).

\section{Quality assessment and risk of bias}

Study quality and risk of bias was assessed using a quality assessment tool developed for the current study (see Supplementary Material 1). The NICE Quality Assessment Checklist for Studies reporting Correlations and Associations (2012) and the NIH Quality Assessment Tool for Observational Cohort and Cross-section Studies (National Heart Lung and Blood Institute, 2014) were used to inform the development of this tool. The assessment framework developed included seven items reflecting: 1) how well the study population was defined; 2) whether an appropriate random sampling or another appropriate recruitment method was utilised; 3) whether non-response rate was reported, was minimal or accounted for (for example, differences between responders and non-responders were non-significant); 4) whether loss to follow-up was minimal in longitudinal studies (i.e. $<20 \%$ ); 5) how reliable was the measure of PTSD; 6) how reliable were the measures of peritraumatic factors; and 7) how soon after the trauma peritraumatic factors were assessed. Each 
item was given a score of $0-2$, with 0 indicating low quality, and 2 indicating high quality and thus low risk of bias. Scores were summed and converted to a percentage; studies scoring more than $70 \%$ were deemed high quality (with low risk of bias), scores of $50-70 \%$ were deemed medium quality (capturing the median score of 58\%), and scores below 50\% were deemed low quality. The researcher (JM) completed quality ratings for all studies, and a second rater (JW) was instructed to use the quality assessment framework to score a random selection of $20 \%(n=7)$ of included studies; there was $83.3 \%$ agreement on all items (kappa=.74).

Within the analysis method, further consideration of risk of bias within the results was also planned; consideration of any evidence of publication bias was planned by generating funnel plots to visually represent the data, with observation of asymmetry in plots and by generating Kendall's tau tests of asymmetry to indicate possible publication bias, and the 'trim-and-fill' method to indicate whether the study sample is missing weaker studies (Duval \& Tweedie, 2000).

\section{Meta-analytic method}

The meta-analysis to examine the relationship between peritraumatic psychological experiences and PTSD symptoms was conducted via user interface software (MAVIS version 1.1.3 (Hamilton, 2017) and OpenMetaAnalyst (Wallace, et al., 2012)) which run the meta-analyses using $\mathrm{R}$ (version 3.4.3) and the 'metafor' (version 2.0.0) package (Viechtbauer, 2010). Random effects models with restricted maximum likelihood estimators of between study variance were used. Extracted $\mathrm{r}$ values entered into the software were transformed into Fisher's $\mathrm{z}$ for the analysis, and transformed back to $\mathrm{r}$ correlation coefficients for reporting of results and interpretation. Heterogeneity of effect sizes was estimated by calculating a Q statistic, whereby if Q is significant $(\mathrm{p}<.05)$ true effect size variation is implicated, and the amount of this variation was estimated by $\mathrm{I}^{2}$. Higgins et al. (2003) suggest that an $\mathrm{I}^{2}$ value of $25 \%$ represents a small degree of heterogeneity, $50 \%$ is moderate, and $75 \%$ represents a large degree of heterogeneity. 
Meta-regression analyses of moderators. Meta-regression was used to explore how certain characteristics of the studies or samples were related to variation seen in the effect sizes reported by the studies. Meta-regression analyses of trauma type (interpersonal vs non-interpersonal), gender (percentage female), mean age, study type (cross-sectional vs prospective), study quality, and time between trauma occurrence and assessment of peritraumatic factors and PTSD, were planned to explore the possible moderating effects of these variables on the strength of the relationship between peritraumatic factors and PTSD.

\section{Results}

\section{Study characteristics}

Thirty-two studies were included, providing a total of 47 effect sizes for the planned metaanalyses estimating the overall strength of the relationship between peritraumatic psychological processes and PTSD symptoms (see Supplementary Material 2 for list of included studies). Table 1 summarises the characteristics of the studies included. Four studies were included which exceeded the typical upper age of 18 years for child and adolescent studies (Elkit \& Kurdahl, 2013; Filkukova, Hafstad \& Jensen, 2016; Nordanger et al., 2014; and Polusny et al., 2011). It was decided to include these four studies as all indicated a mean age of their sample aged 18 years or below, and it was deemed that they provided valuable information about the development of PTSD in adolescent populations. Mean age was planned to be assessed with moderation analyses, and so any effect of older age on the relationship between peritraumatic factors and PTSD would also be indicated. An age-restricted analyses were also conducted, excluding these four studies to explore whether any pertinent difference may be linked to older age, however again it is noted that the mean age of these studies was 18 years or below.

All studies included assessed single event traumas, except two which were regarding trauma related to war or ongoing terror (Soloman \& Lavi, 2005; and Lavi, Green \& Dekel, 2013) in which 
case the number of traumas experienced by individuals was not clear, though both focussed on the participants' experience within the past eight to ten months. The studies spanned a range of trauma types: acute physical injury $(\mathrm{n}=11)$; severe natural disaster (such as an earthquake or hurricane; $\mathrm{n}=12$ ); and exposure to or witnessing severe intentional violence (i.e. war, terror, or homicide; $\mathrm{n}=9$ ). Nineteen studies were cross-sectional (where peritraumatic factors and PTSD were assessed concurrently), and 13 were prospective longitudinal studies. The large majority of studies assessed peritraumatic fear, perceived life threat or helplessness, or a combination of these experiences $(\mathrm{k}=28)$. Twelve of these assessed perceived life threat very specifically, and a further small number assessed peritraumatic dissociation or data-driven processing. The methods used in each study to assess each peritraumatic factor are summarised in Supplementary Material 3.

\section{Assessment of study quality and risk of bias}

All thirty-two included studies were scored against the quality assessment framework. Nine studies were rated as high quality, 19 were rated as medium quality, and four studies were rated as low quality (i.e. high risk of bias). A brief exploration was conducted to identify which items within this quality assessment tool were more consistently rated poorly, by summing the total of scores for this item and calculating the mean score across all studies. Items 6 (how reliable were the measures of peritraumatic factors) and 7 (how soon after the trauma peritraumatic factors were assessed) were rated more poorly across the studies reviewed. Items 1 (the study population being clearly defined), 2 (whether an appropriate random sampling or another appropriate recruitment method was utilised) and 5 (a reliable measure of PTSD utilised) were consistently rated with a higher score across the studies reviewed.

\section{Meta-analyses: peritraumatic subjective threat}

A meta-analysis of all effect sizes related to the experience of the PTSD DSM-IV 'A2' criteria, namely peritraumatic fear, horror, helplessness and perceived life threat, included effect sizes from 28 studies with an overall sample size of 23,744 . An overall effect size of $r=.37$ (95\% 
$\mathrm{CI}=0.31-0.42, \mathrm{z}=11.82, p<0.0001$ ) was estimated (for forest plot see Figure 2). Estimates of heterogeneity showed that there was significant and large variance across the studies $(\mathrm{Q}=493.02$, $\left.\mathrm{df}=27, p<0.001 ; \mathrm{I}^{2}=94.5 \%\right)$.

A funnel plot using the 'trim-and-fill' method was generated and inspected for estimated missing null studies or asymmetry to indicate publication bias in the study sample; minimal asymmetry was identified and just two null studies were estimated as possibly missing. A regression test for funnel plot asymmetry indicated no publication bias $(\mathrm{t}=-0.21, \mathrm{df}=26, p=0.83)$, and Kendall's tau also indicated no significant asymmetry ( $\operatorname{tau}=0.14, p=0.30)$, suggesting no effect of publication bias.

\section{Moderators of the relationship between peritraumatic subjective threat and PTSD.}

Meta-regression analyses were conducted to assess whether gender, age, trauma type, study type, study quality, or time between trauma and assessment of peritraumatic factors or PTSD had any moderating effect on the strength of the relationship between peritraumatic factors and PTSD symptoms. The results of these analyses are summarised in Table 2 . Only female gender played a role in the relationship between peritraumatic subjective threat and fear experiences and the likelihood of PTSD, with greater proportion of females in a study sample leading to larger effect sizes. No other variables had a moderating effect.

\section{Age-restricted analysis.}

This meta-analysis was re-run excluding the four studies which included young people aged over 18 years (Elkit \& Kurdahl, 2013; Filkukova, Hafstad \& Jensen, 2016; Nordanger et al., 2014; and Polusny et al., 2011). This therefore included effect sizes gathered from 24 studies with an overall sample size of 13,548. An overall effect size of $\mathrm{r}=.36(95 \% \mathrm{CI}=.28-.43, \mathrm{z}=8.86, p<.0001)$ was estimated. Estimates of heterogeneity showed that there was significant and large variance across the studies $\left(\mathrm{Q}=453.29, \mathrm{df}=23, p<0.001 ; \mathrm{I}^{2}=94.9 \%\right)$. Therefore, this analysis indicated that there 
wasn't) a noteworthy difference between overall population estimates when these studies were excluded.

\section{Perceived life threat}

A number of studies assessed perceived life threat as a specific single item measure (see Supplementary Material 3); these effect sizes were incorporated in the main peritraumatic subjective meta-analysis reported above, but were also analysed separately to identify an overall estimate of effect size for perceived life threat alone. Twelve studies were included, giving an overall sample size of 15,432. An overall effect size of $r=.37$ (95\% CI=0.32-0.41, z=15.25, $p<0.0001$ ) was estimated by the random effects model (see Figure 3). Estimates of heterogeneity again showed that there was significant and large variance across the studies $(Q=51.55, \mathrm{df}=11$, $\left.p<0.001 ; \mathrm{I}^{2}=78.7 \%\right)$. Inspection of a funnel plot and measures of asymmetry again indicated no significant likely publication bias $(\mathrm{t}=-0.36, \mathrm{df}=10, p=0.73$; Kendall's tau $=0.09, p=0.74)$.

\section{Age-restricted analysis.}

This meta-analysis was re-run excluding two studies which included young people aged over 18 years (Nordanger et al., 2014; and Polusny et al., 2011). This therefore included effect sizes gathered from 10 studies with an overall sample size of 5852. An overall effect size of $r=.35$ (95\% $\mathrm{CI}=.29-.40, \mathrm{z}=10.75, p<.0001)$ was estimated. Estimates of heterogeneity showed that there was significant and large variance across the studies $\left(\mathrm{Q}=38.90, \mathrm{df}=9, p<0.0001 ; \mathrm{I}^{2}=76.9 \%\right)$. Therefore, this analysis indicated that there wasn't a noteworthy difference between overall population estimates when these studies were excluded.

\section{Peritraumatic dissociation}


Five studies reported assessments of the relationship between peritraumatic dissociation and PTSD symptoms in children and adolescents (Brown et al., 2016; Bui et al., 2011; Holmes, Creswell \& O’Connor, 2007; Schäfer, Barkmann, Riedesser, \& Schulte-Markwort, 2004; and Zatzick et al., 2006), with a total sample of 566. All these studies were prospective, assessing peritraumatic dissociation between one to eight weeks post-trauma, and PTSD symptoms up to six months post-trauma. An overall effect size of $\mathrm{r}=.17(95 \% \mathrm{CI}=0.03-0.29, \mathrm{z}=2.44, p<0.05)$ was estimated by the random effects model (see Figure 4). Estimates of heterogeneity suggested some variance across the studies, approaching significance $(\mathrm{Q}=9.27, \mathrm{df}=4, p=0.06)$, and the $\mathrm{I}^{2}$ statistic indicated a moderate degree of heterogeneity (56.8\%). Measures of asymmetry again indicated no significant likely publication bias $(\mathrm{t}=0.099, \mathrm{df}=3, \mathrm{p}=0.93$; Kendall's tau $=0.2, p=0.82)$. Given how few studies considered peritraumatic dissociation, no moderation analyses were undertaken for this variable.

\section{Data-driven processing}

Two studies (total $n=156$ ) were identified which reported results indicative of the relationship between data-driven processing (feeling muddled or confused during or immediately after the trauma) and PTSD symptoms in children and adolescents (Ehlers, Mayou \& Bryant, 2003, and Stallard \& Smith, 2007). Result from a random-effects model suggested an overall effect size estimate of $r=.29(95 \% \mathrm{CI}=0.14-0.43, \mathrm{z}=3.66, p<0.001$; for forest plot see Supplementary Figure 1). Estimates of heterogeneity showed that there was very little variance between the two studies $\left(\mathrm{Q}=0.02, \mathrm{df}=1, p=0.89, \mathrm{I}^{2}=0 \%\right)$. Given how few studies considered data-driven processing, no moderation analyses were undertaken for this variable.

\section{Discussion}

\section{Overall findings}


The current review provided a summary and update of the research currently available pertaining to the relationship between a number of peritraumatic psychological factors and PTSD in children and adolescents. Thirty-two studies published since the DSM first defined PTSD in 1980 were identified as having explored the predictive power of peritraumatic factors in the development of PTSD in children and adolescents, providing 47 effect size estimates for the strength of the relationships between different peritraumatic factors and PTSD. A meta-analysis of all effect sizes related to the experience of the PTSD DSM-IV 'A2' criteria, namely peritraumatic fear, horror, helplessness and perceived life threat, found a medium effect for the relationship between these variables and PTSD ( $r=.37)$. For perceived life threat this was relationship was medium in size $(\mathrm{r}=.37)$. Each of these meta-analyses were characterised by a large degree of heterogeneity. For dissociation the effect size was small $(\mathrm{r}=.17)$. Data driven processing also yielded a small to medium effect $(r=.29)$, but comprised only two studies.

Subjective threat, fear and perceived threat to life. A large proportion of studies identified explored factors which reflected subjective threat and fear responses during trauma as predictors of PTSD symptoms. Our effect size estimate $(r=.37, k=28)$ was similar to the estimate of peritraumatic fear reported by Trickey et al. (2012), reporting a population estimate of effect size of $.36(\mathrm{k}=6)$ for this predictor of PTSD in children and adolescents. Exploration of the effect sizes which were related to the specific measurement of perceive threat to life alone also produced a medium effect size of .37 ; this result again being very similar to the population estimates reported previously both by Trickey et al. (2012) of .36 and Cox et al. (2008) of .38. In a meta-analytic review of predictors of PTSD in adult samples reported lower population estimates (using weighted average correlations between the risk factor and later PTSD symptoms) for both peritraumatic emotional responses (fear, horror, helplessness, guilt or shame) of $r=.26$ (from five studies with a combined $n=1755$ ) and $r=.26$ for peritraumatic perceived life threat (12 studies reviewed with combined n=3524) (Ozer, Best, Lipsey, \& Weiss, 2003). These previous meta-analyses in child and adolescent populations were based on much fewer studies and so a smaller overall sample size. The 
possible inclusion of more studies in the current review also increased the breadth and depth of trauma and participant characteristics assessed. This range of study and participant characteristics, and the random effects analysis model used, supports the generalisability of conclusions to wide ranging populations and trauma experiences.

Overall, the result supports the assertion that the experience of peritraumatic fear responses and perceived threat are likely to play a role in the likelihood of the development of PTSD in children and adolescents, but also suggests that this effect is only moderate. Peritraumatic threat per se is not enough to explain why some youth go on to develop persistent PTSD; it may be that some individuals experience peritraumatic fear or perceived threat and do not develop PTSD, and conversely, that some individuals develop PTSD without the experience of these factors. The removal of the 'A2' criteria from DSM-5 also reflects this possibility (Friedman, et al., 2011).

Peritraumatic dissociation. While dissociative symptoms have been of great interest to theorists and clinicians alike, just five studies were found to have measured peritraumatic dissociation in child and adolescent populations, and an overall sample size of 556 individuals. Our meta-analysis estimated a small effect size, which may be deemed lower than expected considering the previously implicated role of dissociation in previous research and theory of PTSD. Similarly, within adult samples, the effect of peritraumatic dissociation has been estimated as being much greater; a population estimate of $r=.35$ gained from 16 studies (combined $n=3534$ ) was reported by Ozer et al. (2003) and r=.36 reported by Breh and Seidler (2007). The heterogeneity of the studies included in this analysis was moderate, and much less than that found for fear/threat. Two studies reported a non-significant effect of dissociation but reported no effect size, so zero was entered as the statistic for these studies. This method was aimed to reduce over-estimation of effect sizes and avoid bias in the absence of reported statistics, however it may be that in this small sample of studies this may have made the population estimate of effect size more conservative. Considering the small number of studies identified, and that this current review is the first meta-analytic review of peritraumatic dissociation in children and adolescents to date, this may warrant further research. 
Data-driven processing. With just two studies identified as measuring peritraumatic muddled or confused processing of the event (Ehlers, Mayou \& Bryant, 2003, and Stallard \& Smith, 2007), conclusions regarding the power of this experience as a risk factor for PTSD are also limited. However, the results of an estimated small to medium effect size, with two particularly homogenous studies, does indicate that further research into this factor is clearly warranted and necessary to aid better understanding of its role in the development of PTSD.

\section{Moderators of the relationship between peritraumatic factors and PTSD. Our} moderation analysis suggested studies with younger populations were likely to find just as large effect size estimates for subjective threat and fear response as those with older populations. A caveat of conclusions drawn from meta-regression analyses of age is related to the limitation of utilising sample mean age for these analyses; mean age does not comprehensively capture the full range and spread of ages in the samples included. As may have been expected, given female gender has been shown to be a consistent but small predictor of PTSD, more females in a study sample was associated with an increased likelihood of a greater effect size. It is noteworthy that metaregressions exploring the relationship between effect size and study quality suggested no significant difference between the size of the effect found in high versus medium or low quality studies. Moreover, the lack of a moderating effect of period between trauma and peri-trauma variable assessment suggests that recall did not unduly influence our results.

\section{Limitations}

Some limitations are important to note with regards to this study. Firstly, the assessment of peritraumatic factors varied greatly; we identified that most studies used single-item measures of a certain experience, such as feeling fear or data-driven processing, and there were few full and validated measures of peritraumatic experiences. Thus, variance in effect sizes could have been partially attributed to differences and lack of standardisation in assessment. The Peritraumatic 
Distress Inventory (Brunet, Weiss, Metzler, Best, Neylan, Rogers, Fagan, \& Marmar, 2001), and the Peritraumatic Dissociative Experiences Questionnaire (Marmar, Metzler \& Otte, 2004) appeared to be more comprehensive measures of peritraumatic factors available which were utilised in some studies reviewed, and have children's versions with evidence for their reliability and validity (Bui et al., 2011). These two measures may therefore be available measures with utility for further research or clinical practice, as identified from the studies reviewed, however further exploration of the utility, validity and reliability or development of measures to assess peritraumatic experiences for children and young people would be a helpful next step.

Secondly, we cannot confidently conclude that these results may apply to the experience of multiple traumas as all studies included in the present analyses related to single-event traumas, except a handful of studies which related to war. Our study exclusion criteria requiring peritraumatic factors to be assessed within a reasonable time after trauma may have led to the disproportionate exclusion of the types of studies which explore ongoing or multiple trauma experiences in childhood, e.g. abuse. Thirdly, a relatively small number of studies were included in the review; despite this being a significant increase in the number of studies reported by previous meta-analytic reviews of this population (six studies identified by Trickey et al., 2012, and four by Cox et al., 2008). This was particularly true for dissociation and data-driven processing. This review would likely benefit from further updating in the coming years as more research is conducted.

\section{Implications}

The current meta-analytic review supports previous suggestions that certain peritraumatic experiences - particularly experiencing feelings of extreme fear, perceived life threat and possibly confused and muddled processing - are important risk factors for the development of PTSD. These findings are consistent with cognitive models of PTSD which describe how fear responses, perceived threat and poor processing of the event play a role in the development of post-trauma stress symptoms, with post-trauma cognitive processing and behaviours playing a role in the 
maintenance of PTSD (Brewin, et al., 1996; Ehlers \& Clark, 2000). In contrast, the evidence from this review suggests a less pronounced role for peritraumatic dissociation as a risk factor for PTSD. This understanding of the key experiences during trauma which are associated with an increased risk of PTSD may help clinicians and researchers identify which children may be at greater risk of developing PTSD in the acute phase following trauma, by identifying if they had these peritraumatic experiences. However, neither should the importance of peritraumatic psychological process be overstated, since a considerable degree of variance in PTSD severity must be accounted for by other factors; caution must be exercised against assuming that youth who experience very negative emotional reactions during a trauma or a perceived threat to life will automatically go on to develop PTSD.

This identification of those at heightened risk may help to target intervention strategies. Furthermore, this supports the focus of intervention strategies, such as trauma-focussed CBT for children and adolescents, incorporating cognitive restructuring of trauma-related appraisals and reducing fear responses associated with trauma-related stimuli (Cohen, Deblinger, Mannarino, \& Steer, 2004; Smith, et al., 2013). Finally, the conclusions of the present review may be helpfully considered in line with the recent change in the diagnostic requirements of PTSD between DSM-IV and DSM-5, which no longer stipulates the requirement for experiencing fear, helplessness and/or perceived life threat at the time of trauma. The previous measurement of these factors may have been due to researchers' conceptualisation of these experiences as diagnostic necessities, however, these peritraumatic experiences may be more appropriately considered as risk factors for the development of symptoms. We encourage the further exploration of peritraumatic experiences for children and young people, within both qualitative and quantitative research; it would be helpful for researchers and clinicians alike to have better standardised measurement of the range of peritraumatic experiences. This would enable further research and exploration in clinical practice of their role in the development and maintenance of PTSD, and timely identification of whether children and adolescents' experience of trauma was particularly characterised by fear, perceived life 
threat, confused or muddled processing. With further studies assessing peritraumatic experiences, there may also be greater opportunity to further explore mediating and moderating effects of other variables upon the role of peritraumatic experiences in the development of PTSD for children and adolescents, such as age at the time of trauma, trauma type, time between trauma and assessment, or the impact of medical and/or psychological intervention or support. A particular area which this review highlighted as an important next step was for further research exploring the role of data driven processing and dissociation, given the small number of studies identified as having assessed these as risk factors for children. Furthermore, it would be interesting for research to further explore any difference in the role of peritraumatic factors within multiple or prolonged trauma, and how this may be assessed when there may be multiple timepoints for 'within trauma' cognitions, emotional and physiological experiences. Researchers and clinicians are also encouraged to consider the importance of peritraumatic factors as relative in comparison to other pre-trauma, trauma-related and post-trauma factors. 


\section{References}

Alisic, E., Zalta, A. K., van Wesel, F., Larsen, S. E., Hafstad, G. S., Hassanpour, K., \& Smid, G. E. (2014). Rates of post-traumatic stress disorder in trauma-exposed children and adolescents: Meta-analysis. Br J Psychiatry, 204, 335-40.

American Psychiatric Association. (1980). Diagnostic and statistical manual of mental disorders ( $3^{\text {rd }}$ ed.). Washington, DC: Author.

American Psychiatric Association. (2000). Diagnostic and statistical manual of mental disorders ( $4^{\text {th }}$ ed., text rev.). Washington, DC: Author.

American Psychiatric Association. (2013). Diagnostic and statistical manual of mental disorders ( $5^{\text {th }}$ ed.). Washington, DC: Author.

Borenstein, M. (2009). Introduction to meta-analysis. Chichester, U.K.: John Wiley \& Sons.

Borenstein, M., Hedges, L., Higgins, J., \& Rothstein, H. (2009). Introduction to Meta-Analysis, Chapter 7: Converting Among Effect Sizes (pp. 45-49). Chichester: West Sussex, UK: Wiley.

Breh, D. C., \& Seidler, G. H. (2007). Is peritraumatic dissociation a risk factor for PTSD? J Trauma Dissociation, 8, 53-69.

Brewin, C. R., Dalgleish, T., \& Joseph, S. (1996). A dual representation theory of posttraumatic stress disorder. Psychol Rev, 103, 670-86.

Brown, R. C., Nugent, N. R., Hawn, S. E., Koenen, K. C., Miller, A., Amstadter, A. B., \& Saxe, G. (2016). Predicting the transition from acute stress disorder to posttraumatic stress disorder in children with severe injuries. Journal of Pediatric Health Care, 30, 558-68.

Brunet, A., Weiss, D. S., Metzler, T. J., Best, S. R., Neylan, T. C., Rogers, C., ... \& Marmar, C. R. (2001). The Peritraumatic Distress Inventory: a proposed measure of PTSD criterion A2. American Journal of Psychiatry, 158(9), 1480-1485. 
Bryant, B., Mayou, R., Wiggs, L., Ehlers, A., \& Stores, G. (2004). Psychological consequences of road traffic accidents for children and their mothers. Psychol Med, 34, 335-46.

Bryant, R. A. (2007). Does dissociation further our understanding of PTSD? J Anxiety Disord, 21, 183-91.

Bui, É., Brunet, A., Olliac, B., Véry, E., Allenou, C., Raynaud, J.-P., Claudet, I., Bourdet-Loubère, S., Grandjean, H., Schmitt, L., \& Birmes, P. J. (2011). Validation of the Peritraumatic Dissociative Experiences Questionnaire and Peritraumatic Distress Inventory in school-aged victims of road traffic accidents. European Psychiatry, 26, 108-11.

Candel, I., \& Merckelbach, H. (2004). Peritraumatic dissociation as a predictor of post-traumatic stress disorder: a critical review. Compr Psychiatry, 45, 44-50.

Cénat, J. M., \& Derivois, D. (2015). Long-term outcomes among child and adolescent survivors of the 2010 Haitian earthquake. Depression and Anxiety, 32, 57-63.

Cohen, J. (1965). Some statistical issues in psychological research. Handbook of clinical psychology, 95-121.

Cohen, J. (1988). Statistical power analysis for the behavioral sciences (2nd ed.). Hilllsdale, NJ: Erlbaum.

Cohen, J. A., Deblinger, E., Mannarino, A. P., \& Steer, R. A. (2004). A multisite, randomized controlled trial for children with sexual abuse-related PTSD symptoms. J Am Acad Child Adolesc Psychiatry, 43, 393-402.

Copeland, W. E., Keeler, G., Angold, A., \& Costello, E. J. (2007). Traumatic events and posttraumatic stress in childhood. Arch Gen Psychiatry, 64, 577-84.

Costello, E. J., Erkanli, A., Fairbank, J. A., \& Angold, A. (2002). The prevalence of potentially traumatic events in childhood and adolescence. J Trauma Stress, 15, 99-112.

Cox, C. M., Kenardy, J. A., \& Hendrikz, J. K. (2008). A meta-analysis of risk factors that predict psychopathology following accidental trauma. J Spec Pediatr Nurs, 13, 98-110. 
Cuijpers, P. (2016). Meta-analyses in mental health research. A practical guide. Retrieved from https://www.researchgate.net/publication/301815425_Metaanalyses_in_mental_health_research_A_practical_guide?tab=overview

Duval, S., \& Tweedie, R. (2000). Trim and fill: A simple funnel-plot-based method of testing and adjusting for publication bias in meta-analysis. Biometrics, 56, 455-63.

Ehlers, A., \& Clark, D. M. (2000). A cognitive model of posttraumatic stress disorder. Behav Res Ther, 38, 319-45.

Ehlers, A., Mayou, R. A., \& Bryant, B. (2003). Cognitive predictors of posttraumatic stress disorder in children: Results of a prospective longitudinal study. Behaviour Research and Therapy, $41,1-10$.

Elklit, A., \& Kurdahl, S. (2013). The psychological reactions after witnessing a killing in public in a Danish high school. European Journal of Psychotraumatology, 4.

Filkuková, P., Hafstad, G. S., \& Jensen, T. K. (2016). Who can I trust? Extended fear during and after the Utøya terrorist attack. Psychological Trauma: Theory, Research, Practice, and Policy, 8, 512-19.

Foa, E. B., Steketee, G., \& Rothbaum, B. O. (1989). Behavioral/cognitive conceptualizations of post-traumatic stress disorder. Behavior therapy, 20, 155-76.

Foy, D. W., Madvig, B. T., Pynoos, R. S., \& Camilleri, A. J. (1996). Etiologic factors in the development of posttraumatic stress disorder in children and adolescents. Journal of School Psychology, 34, 133-45.

Friedman, M. J., Resick, P. A., Bryant, R. A., \& Brewin, C. R. (2011). Considering PTSD for DSM-5. Depression and Anxiety, 28(9), 750-769. doi:10.1002/da.20767

Hamilton, K. (2017). Meta Analysis via Shiny.

Hedges, L. V., \& Pigott, T. D. (2004). The power of statistical tests for moderators in meta-analysis. Psychol Methods, 9, 426-45. 
Hedges, L. V., \& Vevea, J. L. (1998). Fixed-and random-effects models in meta-analysis. Psychological methods, 3, 486.

Higgins, J., \& Altman, D. G. (2008). Assessing risk of bias in included studies. Cochrane handbook for systematic reviews of interventions: Cochrane book series, 187-241.

Higgins, J. P., Altman, D. G., Gotzsche, P. C., Juni, P., Moher, D., Oxman, A. D., Savovic, J., Schulz, K. F., Weeks, L., Sterne, J. A., Cochrane Bias Methods, G., \& Cochrane Statistical Methods, G. (2011). The Cochrane Collaboration's tool for assessing risk of bias in randomised trials. $B M J, 343, \mathrm{~d} 5928$.

Higgins, J. P., \& Thompson, S. G. (2004). Controlling the risk of spurious findings from metaregression. Stat Med, 23, 1663-82.

Higgins, J. P., Thompson, S. G., Deeks, J. J., \& Altman, D. G. (2003). Measuring inconsistency in meta-analyses. $B M J, 327,557-60$.

Holmes, E. A., Creswell, C., \& O'Connor, T. G. (2007). Posttraumatic stress symptoms in London school children following September 11, 2001: An exploratory investigation of peritraumatic reactions and intrusive imagery. Journal of Behavior Therapy and Experimental Psychiatry, 38, 474-90.

Ishak, K. J., Platt, R. W., Joseph, L., Hanley, J. A., \& Caro, J. J. (2007). Meta-analysis of longitudinal studies. Clinical Trials, 4(5), 525-539.

Keppel-Benson, J. M., Ollendick, T. H., \& Benson, M. J. (2002). Post-traumatic stress in children following motor vehicle accidents. J Child Psychol Psychiatry, 43, 203-12.

Kilpatrick, D. G., Resnick, H. S., Milanak, M. E., Miller, M. W., Keyes, K. M., \& Friedman, M. J. (2013). National estimates of exposure to traumatic events and PTSD prevalence using DSM-IV and DSM-5 criteria. J Trauma Stress, 26, 537-47.

Lavi, T., Green, O., \& Dekel, R. (2013). The contribution of personal and exposure characteristics to the adjustment of adolescents following war. Journal of Adolescence, 36, 21-30. 
Marmar, C. R., Metzler, T. J., \& Otte, C. (2004). The peritraumatic dissociative experiences questionnaire. The Guilford Press.

Moher, D., Liberati, A., Tetzlaff, J., \& Altman, D. G. (2009). Preferred reporting items for systematic reviews and meta-analyses: the PRISMA statement. Annals of internal medicine, 151(4), 264-269.

Musekiwa, A., Manda, S. O., Mwambi, H. G., \& Chen, D. G. (2016). Meta-Analysis of Effect Sizes Reported at Multiple Time Points Using General Linear Mixed Model. PloS one, 11(10), e0164898.

National Heart Lung and Blood Institute. (2014). Quality assessment tool for observational, cohort and cross-sectional studies. Retrieved from https://www.nhlbi.nih.gov/health-topics/studyquality-assessment-tools.

NICE. (2012). Methods for the development of NICE public health guidance.

Nordanger, D. Ø., Breivik, K., Haugland, B. S., Lehmann, S., Mæhle, M., Braarud, H. C., \& Hysing, M. (2014). Prior adversities predict posttraumatic stress reactions in adolescents following the Oslo Terror events 2011. European Journal of Psychotraumatology, 5.

Ogle, C. M., Rubin, D. C., Berntsen, D., \& Siegler, I. C. (2013). The Frequency and Impact of Exposure to Potentially Traumatic Events Over the Life Course. Clin Psychol Sci, 1, 426-34.

Oswald, F. L., \& Plonsky, L. (2010). Meta-analysis in Second Language Research: Choices and Challenges. Annual Review of Applied Linguistics, 30, 85-110.

Ozer, E. J., Best, S. R., Lipsey, T. L., \& Weiss, D. S. (2003). Predictors of posttraumatic stress disorder and symptoms in adults: a meta-analysis. Psychological bulletin, 129(1), 52.

Peterson, R. A., \& Brown, S. P. (2005). On the use of beta coefficients in meta-analysis. J Appl Psychol, 90(1), 175-181. doi:10.1037/0021-9010.90.1.175

Pigott, T. D. (2009). Handling missing data. The handbook of research synthesis and meta-analysis, 2, 399-416. 
Pine, D. S., \& Cohen, J. A. (2002). Trauma in children and adolescents: Risk and treatment of psychiatric sequelae. Biol Psychiatry, 51, 519-31.

Polusny, M. A., Ries, B. J., Meis, L. A., DeGarmo, D., McCormick-Deaton, C. M., Thuras, P., \& Erbes, C. R. (2011). Effects of parents' experiential avoidance and PTSD on adolescent disaster-related posttraumatic stress symptomatology. J Fam Psychol, 25, 220-9.

Rosenthal, R. (1991). Meta-analytic procedures for social research (Vol. 6): Sage.

Rosnow, R. L., \& Rosenthal, R. (1996). Computing contrasts, effect sizes, and counternulls on other people's published data: General procedures for research consumers. Psychological Methods, 1(4), 331.

Saxe, G. N., Stoddard, F., Hall, E., Chawla, N., Lopez, C., Sheridan, R., King, D., King, L., \& Yehuda, R. (2005). Pathways to PTSD, part I: Children with burns. Am J Psychiatry, 162, 1299-304.

Schäfer, I., Barkmann, C., Riedesser, P., \& Schulte-Markwort, M. (2004). Peritraumatic dissociation predicts posttraumatic stress in children and adolescents following road traffic accidents. Journal of Trauma and Dissociation, 5, 79-92.

Scheeringa, M. S., Wright, M. J., Hunt, J. P., \& Zeanah, C. H. (2006). Factors affecting the diagnosis and prediction of PTSD symptomatology in children and adolescents. Am J Psychiatry, 163, 644-51.

Smith, P., Perrin, S., Dalgleish, T., Meiser-Stedman, R., Clark, D. M., \& Yule, W. (2013). Treatment of posttraumatic stress disorder in children and adolescents. Curr Opin Psychiatry, 26, 66-72.

Solomon, Z., \& Lavi, T. (2005). Israeli youth in the Second Intifada: PTSD and future orientation. $J$ Am Acad Child Adolesc Psychiatry, 44, 1167-75.

Stallard, P., \& Smith, E. (2007). Appraisals and cognitive coping styles associated with chronic post-traumatic symptoms in child road traffic accident survivors. Journal of Child Psychology and Psychiatry, 48, 194-201. 
Trickey, D., Siddaway, A. P., Meiser-Stedman, R., Serpell, L., \& Field, A. P. (2012). A metaanalysis of risk factors for post-traumatic stress disorder in children and adolescents. Clin Psychol Rev, 32, 122-38.

Valentine, J. C., Pigott, T. D., \& Rothstein, H. R. (2010). How many studies do you need? A primer on statistical power for meta-analysis. Journal of Educational and Behavioral Statistics, 35, 215-47.

Viechtbauer, W. (2010). Conducting meta-analyses in R with the metafor package. J Stat Softw, 36, $1-48$.

Wallace, B. C., Dahabreh, I. J., Trikalinos, T. A., Lau, J., Trow, P., \& Schmid, C. H. (2012).

Closing the gap between methodologists and end-users: R as a computational back-end. $J$ Stat Softw, 49, 1-15.

World Health Organization. (1992). The ICD-10 Classification of Mental and Behavioural Disorders: Clinical Descriptions and Diagnostic Guidelines. Geneva: WHO.

Zatzick, D. F., Grossman, D. C., Russo, J., Pynoos, R., Berliner, L., Jurkovich, G., Sabin, J. A., Katon, W., Ghesquiere, A., McCauley, E., \& Rivara, F. P. (2006). Predicting posttraumatic stress symptoms longitudinally in a representative sample of hospitalized injured adolescents. Journal of the American Academy of Child \& Adolescent Psychiatry, 45, 1188 95. 
Table 1. Characteristics of studies included in the meta-analyses.

\begin{tabular}{|c|c|c|c|c|c|c|c|c|c|c|c|c|}
\hline Article & $\begin{array}{l}\text { Peri-traumatic } \\
\text { risk factors } \\
\text { assessed }\end{array}$ & Trauma type & $\mathbf{N}$ & $\begin{array}{l}\text { Age } \\
\text { range }\end{array}$ & $\begin{array}{l}\text { Mean } \\
\text { age } \\
\text { (SD) }\end{array}$ & $\begin{array}{l}\% \\
\text { female }\end{array}$ & Country & Study type & $\begin{array}{l}\text { Time } \\
\text { between } \\
\text { trauma \& } \\
\text { initial } \\
\text { assessment }\end{array}$ & $\begin{array}{l}\text { Time between } \\
\text { assessment of } \\
\text { peritraumatic } \\
\text { factor and } \\
\text { PTSD } \\
\text { assessment }\end{array}$ & $\begin{array}{l}\text { PTSD } \\
\text { measure }\end{array}$ & $\begin{array}{l}\text { Interview } \\
\text { or self- } \\
\text { report } \\
\text { question- } \\
\text { naire }\end{array}$ \\
\hline $\begin{array}{l}\text { Aaron, Zaglul, \& } \\
\text { Emery (1999) }\end{array}$ & Fear & $\begin{array}{l}\text { Acute physical } \\
\text { injury (RTA, } \\
\text { physical assault } \\
\text { or other } \\
\text { accidental injury) }\end{array}$ & 40 & $8-17$ & $\begin{array}{l}13.6 \\
(2.9)\end{array}$ & $52.5 \%$ & US & $\mathrm{CS}$ & 4 weeks & 0 & PTSD-RI & Self-report \\
\hline $\begin{array}{l}\text { Bödvarsdóttir, } \\
\text { Elklit, \& } \\
\text { Gudmundsdóttir } \\
\text { (2006) }\end{array}$ & $\begin{array}{l}\text { Fear of dying; } \\
\text { Terror; } \\
\text { helplessness }\end{array}$ & $\begin{array}{l}\text { Natural disaster: } \\
\text { earthquake }\end{array}$ & 140 & $10-15$ & $\begin{array}{l}12.2 \\
(1.6)\end{array}$ & $55 \%$ & Iceland & CS & 3 months & 0 & CPTS-RI & Self-report \\
\hline $\begin{array}{l}\text { Brown, et al. } \\
(2016)\end{array}$ & Dissociation & $\begin{array}{l}\text { Acute physical } \\
\text { injury (burns and } \\
\text { other accidental } \\
\text { injuries) }\end{array}$ & 204 & $7-18$ & $\begin{array}{l}13.5 \\
(3.5)\end{array}$ & $25.7 \%$ & US & $\begin{array}{l}\text { PL }(F U \text { at } 3, \\
6,12,18 \\
\text { mnths })\end{array}$ & $<1$ week & 12 weeks & DICA-PTSD & Interview \\
\hline Bui, et al. (2011) & Distress & RTA & 133 & $8-15$ & $\begin{array}{l}11.7 \\
(2.2)\end{array}$ & $43.6 \%$ & France & $\begin{array}{l}\text { PL (FU at } 5 \\
\text { wks) }\end{array}$ & $<1$ week & 5 weeks & CPTS-RI & Self-report \\
\hline $\begin{array}{l}\text { Cénat and } \\
\text { Derivois (2015) }\end{array}$ & Distress & $\begin{array}{l}\text { Natural disaster } \\
\text { (earthquake) }\end{array}$ & 872 & $7-17$ & $\begin{array}{l}14.9 \\
(1.9)\end{array}$ & $56.3 \%$ & Haiti & $\mathrm{CS}$ & 30 months & 0 & IES-R & Self-report \\
\hline Duffy, et al. (2015) & PLT & Terror attack & 2095 & $14-18$ & $\begin{array}{l}15.9 \\
(1.2)\end{array}$ & $52.3 \%$ & Ireland & $\mathrm{CS}$ & 15 months & 0 & PDS & Self-report \\
\hline $\begin{array}{l}\text { Ehlers, Mayou, \& } \\
\text { Bryant (2003) }\end{array}$ & $\begin{array}{l}\text { Data-driven } \\
\text { processing; } \\
\text { PLT; fear }\end{array}$ & RTA & 81 & $5-16$ & $\begin{array}{l}12.3 \\
(2.9)\end{array}$ & $45 \%$ & UK & $\begin{array}{l}\mathrm{PL}(\mathrm{FU} \text { at } 3,6 \\
\text { mnths) }\end{array}$ & 2 weeks & 10 weeks & IES-R & Self-report \\
\hline $\begin{array}{l}\text { Elklit \& Kurdahl } \\
\text { (2013) }\end{array}$ & $\begin{array}{l}\text { PTSD A2 } \\
\text { criteria: fear, } \\
\text { helplessness, } \\
\text { horror \& PLT }\end{array}$ & $\begin{array}{l}\text { Witnessing a } \\
\text { homicide }\end{array}$ & 320 & $16-20$ & $\begin{array}{l}17.9 \\
(1.1)\end{array}$ & $62.2 \%$ & Denmark & $\mathrm{CS}$ & 7 months & 0 & $\begin{array}{l}\text { Harvard } \\
\text { Trauma } \\
\text { Question- } \\
\text { naire }\end{array}$ & Self-report \\
\hline $\begin{array}{l}\text { Evans \& Oehler- } \\
\text { Stinnett (2006) }\end{array}$ & Fear & $\begin{array}{l}\text { Natural disaster } \\
\text { (tornado) }\end{array}$ & 152 & $6-12$ & 9.5 & $51.3 \%$ & US & $\mathrm{CS}$ & 12 months & 0 & $\begin{array}{l}\text { OSU PTSDS- } \\
\text { CF }\end{array}$ & Self-report \\
\hline $\begin{array}{l}\text { Filkuková, et al. } \\
\text { (2016) }\end{array}$ & Fear & Terror attack & 296 & $13-26$ & 18.4 & $48.6 \%$ & Norway & $\mathrm{CS}$ & 4-5 months & 0 & PTSD-RI & Self-report \\
\hline $\begin{array}{l}\text { Giannopoulou, et } \\
\text { al. (2006) }\end{array}$ & PLT; distress & $\begin{array}{l}\text { Natural disaster } \\
\text { (earthquake) }\end{array}$ & 2037 & $9-17$ & 12.9 & $48.7 \%$ & Greece & $\mathrm{CS}$ & 6-7 months & 0 & CRIES-13 & Self-report \\
\hline
\end{tabular}




\begin{tabular}{|c|c|c|c|c|c|c|c|c|c|c|c|c|}
\hline $\begin{array}{l}\text { Holmes, et al. } \\
(2007)\end{array}$ & $\begin{array}{l}\text { Fear; PLT; } \\
\text { helplessness; } \\
\text { derealisation }\end{array}$ & $\begin{array}{l}\text { Witnessing a } \\
\text { terror attack (911 } \\
\text { on TV) }\end{array}$ & 76 & $10-11$ & & $51.3 \%$ & UK & $\begin{array}{l}\mathrm{PL}(\mathrm{FU} \text { at } 6 \\
\text { mnths) }\end{array}$ & 2 months & 16 weeks & CPSS & Self-report \\
\hline Kar, et al. (2007) & $\begin{array}{l}\text { Fear of life } \\
\text { threat }\end{array}$ & $\begin{array}{l}\text { Natural disaster } \\
\text { (cyclone) }\end{array}$ & 447 & $7-17$ & $\begin{array}{l}12.9 \\
(1.8)\end{array}$ & $50.7 \%$ & India & $\mathrm{CS}$ & 12 months & 0 & $\begin{array}{l}\text { Semi- } \\
\text { structured } \\
\text { psychiatric } \\
\text { interview }\end{array}$ & $\begin{array}{l}\text { Interview } \\
\text { and self- } \\
\text { report }\end{array}$ \\
\hline $\begin{array}{l}\text { Lack \& Sullivan } \\
(2007)\end{array}$ & Fear & $\begin{array}{l}\text { Natural disaster } \\
\text { (tornado) }\end{array}$ & 102 & $8-12$ & $\begin{array}{l}10.4 \\
(1.2)\end{array}$ & $52.7 \%$ & US & $\mathrm{CS}$ & 13 months & 0 & PTSD-RI & Self-report \\
\hline $\begin{array}{l}\text { La Greca, } \\
\text { Silverman, } \\
\text { Vernberg, \& } \\
\text { Prinstein (1996) }\end{array}$ & PLT & $\begin{array}{l}\text { Natural disaster } \\
\text { (hurricane) }\end{array}$ & 442 & $\begin{array}{l}(\mathrm{US} \\
\text { grades } \\
3-5)\end{array}$ & & $57.6 \%$ & US & $\begin{array}{l}\text { PL(FU at } 7, \\
10 \text { mnths) }\end{array}$ & 3 months & 16 weeks & PTSD-RI & Self-report \\
\hline $\begin{array}{l}\text { Lavi, Green, \& } \\
\text { Dekel (2013) }\end{array}$ & Fear & War & 2314 & $12-15$ & $\begin{array}{l}13.5 \\
(0.7)\end{array}$ & $51.6 \%$ & Lebanon & $\mathrm{CS}$ & 8-10 months & 0 & CPTS-RI & Self-report \\
\hline $\begin{array}{l}\text { Marsac, et al. } \\
\text { (2017) }\end{array}$ & $\begin{array}{l}\text { Shock/horror, } \\
\text { helplessness, } \\
\text { fear, PLT }\end{array}$ & $\begin{array}{l}\text { Acute physical } \\
\text { injury } \\
\text { (accidental: RTA } \\
\text { or other accident) }\end{array}$ & 96 & $8-13$ & $\begin{array}{l}10.6 \\
(1.7)\end{array}$ & $35.4 \%$ & US & $\begin{array}{l}\text { PL(FU at } 6, \\
12 \text { wks) }\end{array}$ & 2 weeks & 10 & CPSS & Self-report \\
\hline $\begin{array}{l}\text { McDermott, Lee, } \\
\text { Judd, \& Gibbon } \\
\text { (2005) }\end{array}$ & PLT & $\begin{array}{l}\text { Natural disaster } \\
\text { (wildfire) }\end{array}$ & 222 & $8-18$ & $\begin{array}{l}12.5 \\
(2.5)\end{array}$ & $54.9 \%$ & Canada & $\mathrm{CS}$ & 6 months & 0 & PTSD-RI & Self-report \\
\hline $\begin{array}{l}\text { McDermott Sales, } \\
\text { Fivush, Parker, \& } \\
\text { Bahrick (2005) }\end{array}$ & $\begin{array}{l}\text { Stress (scared/ } \\
\text { upset/ } \\
\text { frightened) }\end{array}$ & $\begin{array}{l}\text { Natural disaster } \\
\text { (hurricane) }\end{array}$ & 35 & $3-4$ & $\begin{array}{l}4.25 \\
(0.6)\end{array}$ & $40 \%$ & US & $\begin{array}{l}\text { PL } \\
\text { (FU at } 6 \text { yrs) }\end{array}$ & $2-5$ months & $\begin{array}{l}\text { approx. } 300 \\
\text { weeks }\end{array}$ & CPTSD-RI & Self-report \\
\hline $\begin{array}{l}\text { Meiser-Stedman, } \\
\text { Dalgleish, } \\
\text { Glucksman, Yule, } \\
\text { \& Smith (2009) }\end{array}$ & $\begin{array}{l}\text { Subjective } \\
\text { severity of } \\
\text { threat (PLT, } \\
\text { threat of harm } \\
\text { and scared) }\end{array}$ & $\begin{array}{l}\text { RTA or physical } \\
\text { assault }\end{array}$ & 59 & $10-16$ & $\begin{array}{l}14 \\
(1.9)\end{array}$ & $45.8 \%$ & UK & $\begin{array}{l}\mathrm{PL}(\mathrm{FU} \text { at } 6 \\
\text { mnths) }\end{array}$ & 2-4 weeks & 20-22 weeks & ADIS-C & Interview \\
\hline $\begin{array}{l}\text { Nordanger, et al. } \\
\text { (2014) }\end{array}$ & PLT & Terror attack & 9186 & $17-19$ & $\begin{array}{l}16.9 \\
(0.9)\end{array}$ & $53 \%$ & Norway & $\mathrm{CS}$ & 7 months & 0 & $\begin{array}{l}3 \text { items from } \\
\text { UCLA- } \\
\text { PTSD-RI }\end{array}$ & Self-report \\
\hline $\begin{array}{l}\text { Pfefferbaum, et } \\
\text { al. (2003) }\end{array}$ & $\begin{array}{l}\text { Peritraumatic } \\
\text { 'reaction' }\end{array}$ & Terror attack & 793 & $9-17$ & $\begin{array}{l}11.43 \\
(1.5)\end{array}$ & $57 \%$ & Kenya & $\mathrm{CS}$ & 8-14 months & 0 & PTSS & Self-report \\
\hline $\begin{array}{l}\text { Pfefferbaum, et } \\
\text { al. (2002) }\end{array}$ & $\begin{array}{l}\text { Peritraumatic } \\
\text { 'reaction' }\end{array}$ & Terror attack & 2381 & $\begin{array}{l}\text { (US } \\
\text { grade } \\
6-8)\end{array}$ & & $56 \%$ & US & $\mathrm{CS}$ & 7 weeks & 0 & PTSS & Self-report \\
\hline $\begin{array}{l}\text { Polusny, et al. } \\
\text { (2011) }\end{array}$ & PLT & $\begin{array}{l}\text { Natural disaster } \\
\text { (tornado) }\end{array}$ & 394 & $12-19$ & $\begin{array}{l}15.3 \\
(1.8)\end{array}$ & $59 \%$ & US & $\mathrm{CS}$ & 6 months & 0 & IES-R & Self-report \\
\hline
\end{tabular}




\begin{tabular}{|c|c|c|c|c|c|c|c|c|c|c|c|c|}
\hline $\begin{array}{l}\text { Schäfer, } \\
\text { Barkmann, } \\
\text { Riedesser, \& } \\
\text { Schulte- } \\
\text { Markwort (2004) }\end{array}$ & Dissociation & RTA & 45 & $8-18$ & $\begin{array}{l}13 \\
(3.2)\end{array}$ & $44 \%$ & Germany & $\begin{array}{l}\text { PL (FU at } 3 \\
\text { mnths) }\end{array}$ & 1 week & 11 weeks & IES-R & Self-report \\
\hline $\begin{array}{l}\text { Solomon \& Lavi } \\
(2005)\end{array}$ & PLT/danger & War/terror & 740 & $11-15$ & & $49-54 \%$ & Israel & CS & $\begin{array}{l}\text { unclear } \\
\text { (maximum } 10 \\
\text { months) }\end{array}$ & 0 & CPTSD-RI & Self-report \\
\hline $\begin{array}{l}\text { Stallard, } \\
\text { Velleman, \& } \\
\text { Baldwin (1998) }\end{array}$ & PLT & RTA & 119 & $5-18$ & & $43 \%$ & UK & CS & $\begin{array}{l}\text { 22-79 days } \\
\text { (mean 40) }\end{array}$ & 0 & CAPS-CA & Interview \\
\hline $\begin{array}{l}\text { Stallard \& Smith } \\
(2007)\end{array}$ & $\begin{array}{l}\text { Data-driven } \\
\text { processing; } \\
\text { perceived harm } \\
\& \text { PLT, how } \\
\text { frightened/ } \\
\text { scared }\end{array}$ & RTA & 75 & $7-18$ & $\begin{array}{l}14 \\
(3.4)\end{array}$ & $50.7 \%$ & UK & CS & 8 months & 0 & CAPS-CA & Interview \\
\hline $\begin{array}{l}\text { Thienkrua, et al. } \\
\text { (2006) }\end{array}$ & $\begin{array}{l}\text { PLT; feeling } \\
\text { helpless (unable } \\
\text { to escape); } \\
\text { panic or fear }\end{array}$ & $\begin{array}{l}\text { Natural disaster } \\
\text { (tsunami) }\end{array}$ & 371 & $7-14$ & 10.4 & $54 \%$ & Thailand & $\begin{array}{l}\text { PL(FU at } 9 \\
\text { mnths) }\end{array}$ & 2 months & 28 weeks & PTSD-RI & Self-report \\
\hline $\begin{array}{l}\text { Winston, Kassam- } \\
\text { Adams, García- } \\
\text { España, } \\
\text { Ittenbach, \& } \\
\text { Cnaan (2003) }\end{array}$ & PLT; fear & RTA & 269 & $8-17$ & $\begin{array}{l}11.4 \\
(2.6)\end{array}$ & $23 \%$ & US & $\begin{array}{l}\text { PL(FU at } 3 \\
\text { mnths) }\end{array}$ & 1 month & 8 weeks & CAPS-CA & Interview \\
\hline $\begin{array}{l}\text { Zatzick, et al. } \\
(2006)\end{array}$ & Dissociation & $\begin{array}{l}\text { Acute injury } \\
\text { (assault/RTA) }\end{array}$ & 108 & $12-18$ & $\begin{array}{l}15.9 \\
(1.9)\end{array}$ & $32 \%$ & US & $\begin{array}{l}\text { PL(FU at } 2, \\
5,12 \text { mnths })\end{array}$ & $<3$ weeks & 5 weeks & PTSD-RI & Self-report \\
\hline $\begin{array}{l}\text { Zhou, Zhang, } \\
\text { Wei, Liu, \& } \\
\text { Hannak (2016) }\end{array}$ & Fear & $\begin{array}{l}\text { Natural disaster } \\
\text { (earthquake) }\end{array}$ & 197 & & $\begin{array}{l}13.2 \\
(1.6)\end{array}$ & $53.3 \%$ & China & $\begin{array}{l}\text { PL(FU at } 2, \\
6,12 \text { mnths })\end{array}$ & 2 weeks & 6 weeks & PTSD-RI & Self-report \\
\hline
\end{tabular}

Note. ADIS-C = Anxiety Disorders Interview Schedule for Children; CAPS-CA = Clinical Administered PTSD Scale, child/adolescent version; CPSS = Children PTSD Symptom Scale; CPTS-RI = Posttraumatic Stress Reaction Index for Children; CRIES-13 = Children's Revised Impacted of Event Scale, 13-item; CS = Cross-sectional; DICA-PTSD = Diagnostic Interview for PTSD in Children \& Adolescents (DICAPTSD) FU = Follow up; IES-R 
= Impact of Events Scale, Revised; OSU PTSDS-CF = Oklahoma State University Post-Traumatic Stress Disorder Scale-Child Form; PDS = Posttraumatic Diagnostic Scale; PL = Prospective longitudinal; PLT = Perceived life threat; PTSD-RI = The UCLA PTSD Reaction Index; RTA = Road traffic accident. 
Table 2. Results of meta-regression analyses of moderators on the strength of the relationship between peritraumatic subjective threat ('A2') factors and PTSD symptoms.

\begin{tabular}{|c|c|c|c|c|c|}
\hline Moderator & Estimate (r) & SE & I.CI & u.CI & $\mathbf{p}$ \\
\hline \multicolumn{6}{|l|}{ Continuous moderators } \\
\hline$\%$ Female & 0.008 & 0.004 & 0.001 & 0.016 & 0.036 \\
\hline Mean age & 0.017 & 0.014 & -0.010 & 0.044 & 0.218 \\
\hline $\begin{array}{l}\text { Time between trauma and assessment of } \\
\text { peritraumatic factors }\end{array}$ & 0.002 & 0.001 & -0.001 & 0.004 & 0.154 \\
\hline \multicolumn{6}{|l|}{ assessed and PTSD assessed } \\
\hline \multicolumn{6}{|l|}{ Categorical moderators } \\
\hline \multicolumn{6}{|l|}{ Study Quality (High vs other) } \\
\hline High $(k=6)$ & 0.351 & 0.081 & 0.206 & 0.482 & \\
\hline Medium or Low (k=22) & 0.374 & 0.039 & 0.306 & 0.437 & \\
\hline Meta-regression coefficient & 0.026 & 0.090 & -0.149 & 0.198 & 0.773 \\
\hline \multicolumn{6}{|l|}{ Study Type } \\
\hline Cross-sectional (k=18) & 0.404 & 0.041 & 0.336 & 0.468 & \\
\hline Prospective $(\mathrm{k}=10)$ & 0.294 & 0.059 & 0.185 & 0.395 & \\
\hline Meta-regression coefficient & -0.125 & 0.071 & -0.259 & 0.015 & 0.079 \\
\hline \multicolumn{6}{|c|}{ Trauma Type (Interpersonal vs non-interpersonal) } \\
\hline Non-interpersonal $(\mathrm{k}=19)$ & 0.361 & 0.043 & 0.285 & 0.433 & \\
\hline Interpersonal $(\mathrm{k}=8)$ & 0.378 & 0.062 & 0.268 & 0.477 & \\
\hline Meta-regression coefficient & 0.018 & 0.076 & -0.129 & 0.165 & 0.808 \\
\hline
\end{tabular}




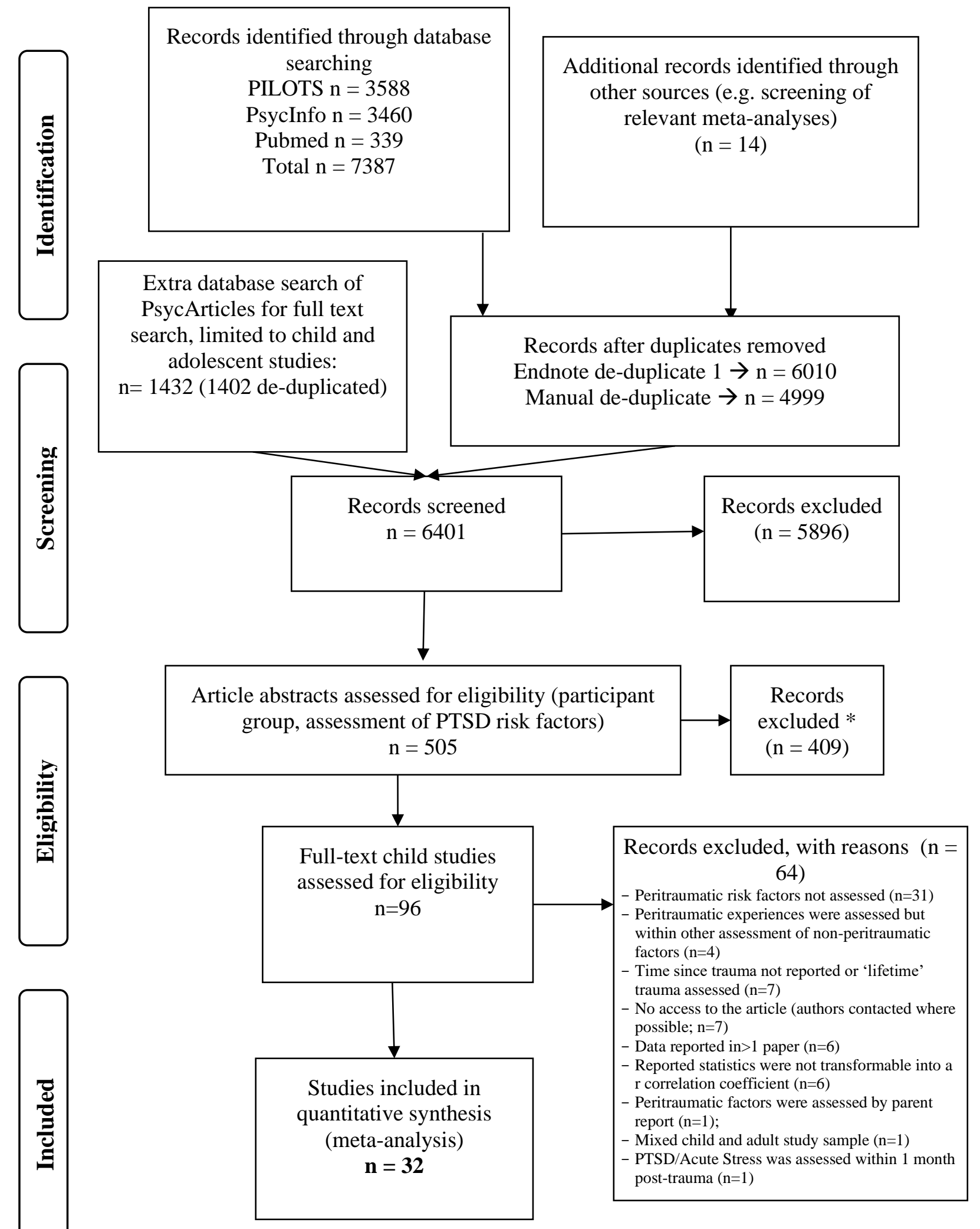

Figure 1. PRISMA flow chart. 
*Articles excluded from initial screening of abstracts if it was not a child or adolescent sample, or it was deemed unlikely that predictors of PTSD were assessed within the study, or another eligibility criterion was clearly ruled out from information given in the abstract. 


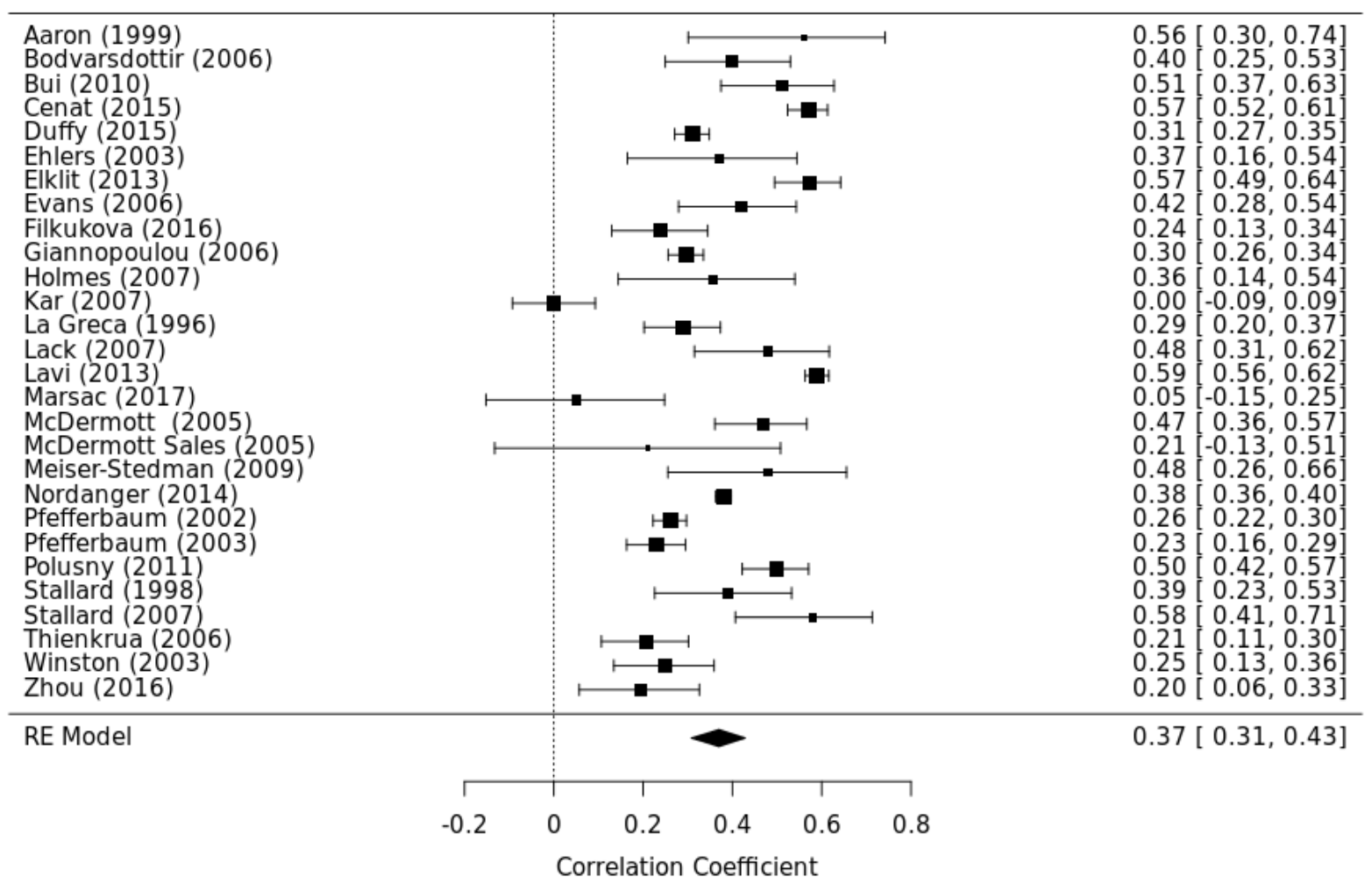

Figure 2. Forest plot for meta-analysis of peritraumatic subjective threat. Illustrating effect sizes (r) sourced from each study, and the estimated overall effect size of the relationship between peritraumatic subjective threat and PTSD symptoms in children and adolescents. 


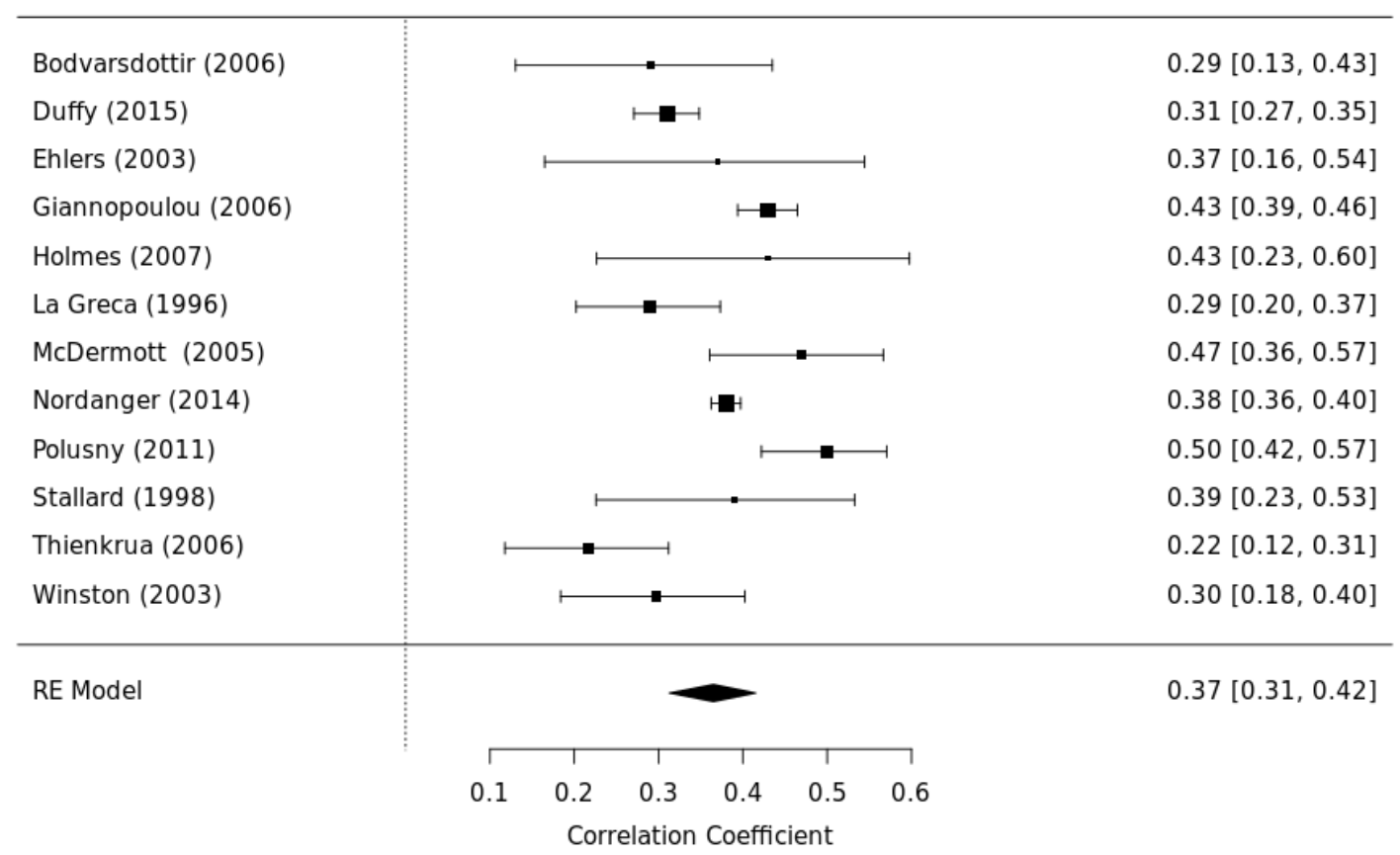

Figure 3. Forest plot for meta-analysis of peritraumatic perceived life threat. Illustrating effect sizes (r) from each study and the overall estimate of the effect size for the relationship between peritraumatic perceived life threat and PTSD symptoms in children and adolescents. 


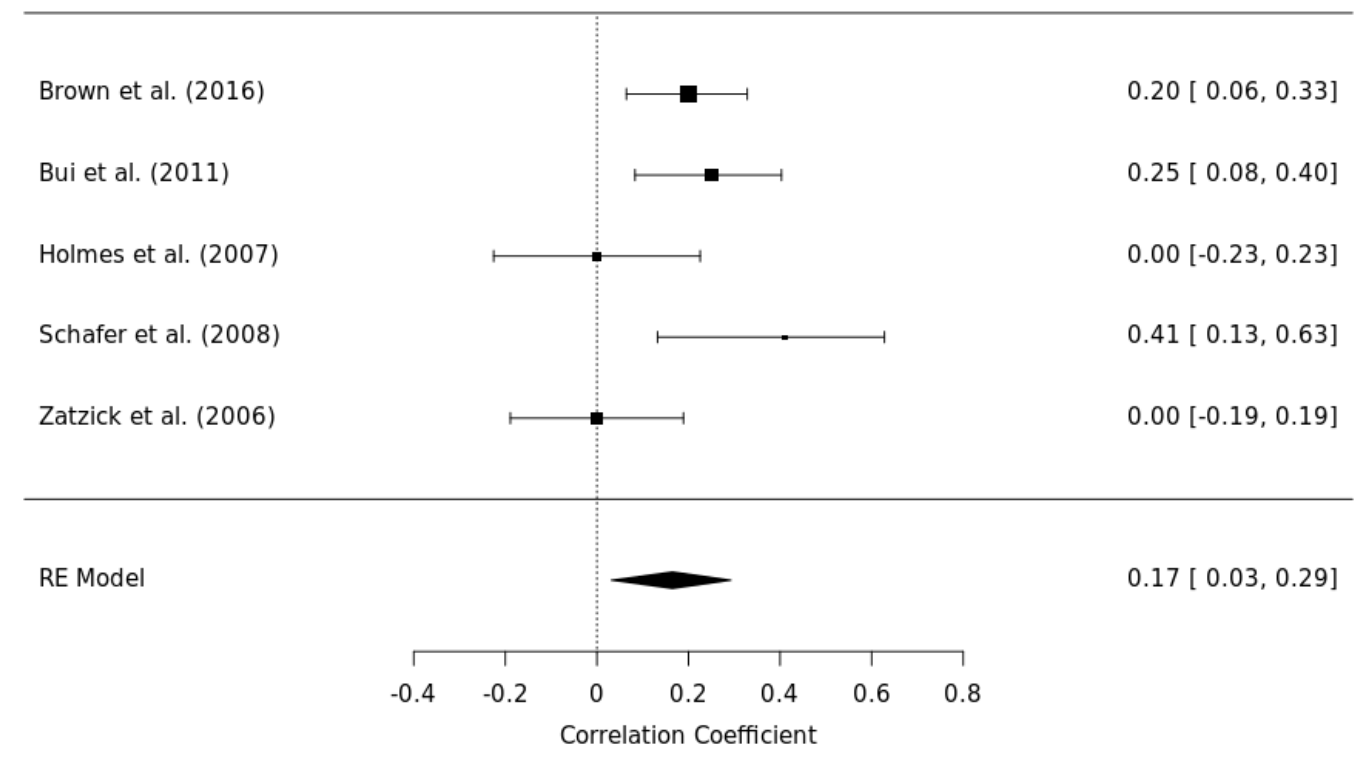

Figure 4. Forest plot for meta-analysis of peritraumatic dissociation. Illustrating effect sizes (r) from each study and the overall estimate of the effect size for the relationship between peritraumatic dissociation and PTSD symptoms in children and adolescents. 
1. Was the study population clearly defined? (consider clear description of age, gender, location, ethnicity, demographics)

Yes- descriptive statistics reported on participant demographics (including age range and mean, gender split) and trauma characteristics (type of trauma, injuries or impact, if natural disaster indicates some level of exposure)

Some descriptive statistics reported but some missing information.

No clear description of sample and trauma characteristics

2 Was some form of random selection used to select the sample or a method of sampling appropriate to the study? (consider random, cluster, or systematic sampling, consecutive recruitment if appropriate, or approached all eligible participants if possible, for example approached all students involved in a specific trauma occurring at one school)

Clear report given on random selection method or appropriate recruitment strategy

Some sampling method used, but not totally random

Unclear whether appropriate sampling method was used, or inappropriate or non-random sampling method used

3 Was non-response bias minimal or accounted for? (consider if the response rate was $>40 \%$. If response rate was an analysis was $<40 \%$, consider if authors assessed and reported no significant difference between responders and non-responders in key indicators e.g. age, gender, trauma type)

Yes; more than $40 \%$ of eligible and approached participants took part and, if reported, there were no significant differences between those who took part and those who did not.

No but accounted for; less than $40 \%$ of those approached took part, but there were no significant differences between those who participated and those who did not.

No; less than $40 \%$ of those approached took part, and differences between those who took part and those who did not were not reported or highlighted significant differences.

Or, response rate was not reported.

4 For longitudinal/prospective studies: was loss to follow-up 20\% or less?

Yes; participant drop-out or non-response was less than $20 \%$.

No, but accounted for; loss to follow up was more than $20 \%$ (but less than $40 \%$ ) but differences between those who completed the full study and those who did not were assessed and reported as showing no significant differences in key indicators (e.g. in age, gender, trauma characteristics or symptoms)

No; loss to follow up was more than $20 \%$ and difference between complete cases and incomplete cases were not assessed or reported, or showed significant differences.

Not applicable; this was a cross-sectional study 
No; a poorly validated or unknown measure of PTSD was used.

6.i Was the measure of peri-traumatic factors reliable? (Consider how well the authors described this measurement; if a validated full-scale, or multiple items from another scale, or just a single item was used to assess each peri-traumatic factor; and consider if this was assessed by interview or self-report measure)

*If multiple peri-traumatic factors are assessed in one study, please complete this question for each factor, labelling each factor assessed here:

Peri-traumatic factor (e.g. fear, perceived life threat...):

A specific and validated full-scale measure (self-report or interview), or multiple items from a semi-structured interview was used to assess peritraumatic factors.

A total or mean score from multiple self-report items, either designed specifically for the study or taken from within an existing measure (with good internal consistency for these items, if reported)

or

A score from a single item from an existing and validated measure

Response on a single item or another single way of assessing a peri-traumatic factors was used, or poor description was given of how this factor was assessed.

6.ii Was the measure of peri-traumatic factors reliable? (Consider how well the authors described this measurement; if a validated full-scale, or multiple items from another scale, or just a single item was used to assess each peri-traumatic factor; and consider if this was assessed by interview or self-report measure)

*If multiple peri-traumatic factors are assessed in one study, please complete this question for each factor, labelling each factor assessed here:

Peri-traumatic factor (e.g. fear, perceived life threat...):

A specific and validated full-scale measure (self-report or interview), or multiple items from a semi-structured interview was used to assess peritraumatic factors.

A total or mean score from multiple self-report items, either designed specifically for the study or taken from within an existing measure (with good internal consistency for these items, if reported)

or

A score from a single item from an existing and validated measure

Response on a single item or another single way of assessing a peri-traumatic factors was used, or poor description was given of how this factor was assessed.

6.iii Was the measure of peri-traumatic factors reliable? (Consider how well the authors described this measurement; if a validated full-scale, or multiple items from another scale, or just a single item was used to assess each peri-traumatic factor; and consider if this was assessed by interview or self-report measure)

*If multiple peri-traumatic factors are assessed in one study, please complete this question for each factor, labelling each factor assessed here:

Peri-traumatic factor (e.g. fear, perceived life threat...):

A specific and validated full-scale measure (self-report or interview), or multiple items from a semi-structured interview was used to assess peritraumatic factors.

A total or mean score from multiple self-report items, either designed specifically for the study or taken from within an existing measure (with good internal consistency for these items, if reported) or

A score from a single item from an existing and validated measure 
Response on a single item or another single way of assessing a peri-traumatic factors was used, or poor description was given of how this factor was assessed.

7 Was the measure of peri-traumatic factors taken within a reasonable time period after the trauma?

Yes; peri-traumatic factors were assessed within 2 weeks since the trauma Peri-traumatic factors were assessed $>2$ weeks but $<4$ weeks since the trauma Peri-traumatic factors were assessed $>1$ month since the trauma

2
1

0

\section{Total Quality Assessment score}

(*note if different total score according to different peri-traumatic factor) For longitudinal studies: $/ 14$

$=\quad \%$

For cross-sectional studies:

$>70 \%=$ high quality study

$=\quad 112$

$50-70 \%=$ medium quality study

$<50 \%=$ low quality study 
Supplementary Material 2. References for studies included in the meta-analyses but not cited within the article text.

Aaron, J., Zaglul, H., \& Emery, R. E. (1999). Posttraumatic stress in children following acute physical injury. J Pediatr Psychol, 24, 335-43.

Bödvarsdóttir, Í., Elklit, A., \& Gudmundsdóttir, D. B. (2006). Post-traumatic Stress Reactions in Children after two large Earthquakes in Iceland. Nordic Psychology, 58, 91-107.

Duffy, M., McDermott, M., Percy, A., Ehlers, A., Clark, D. M., Fitzgerald, M., \& Moriarty, J. (2015). The effects of the Omagh bomb on adolescent mental health: A school-based study. BMC Psychiatry, 15.

Evans, L. G., \& Oehler-Stinnett, J. (2006). Structure and prevalence of PTSD symptomology in children who have experienced a severe tornado. Psychology in the Schools, 43, 283-95.

Giannopoulou, I., Strouthos, M., Smith, P., Dikaiakou, A., Galanopoulou, V., \& Yule, W. (2006). Post-traumatic stress reactions of children and adolescents exposed to the Athens 1999 earthquake. European Psychiatry, 21, 160-66.

Kar, N., Mohapatra, P. K., Nayak, K. C., Pattanaik, P., Swain, S. P., \& Kar, H. C. (2007). Posttraumatic stress disorder in children and adolescents one year after a super-cyclone in Orissa, India: Exploring cross-cultural validity and vulnerability factors. BMC Psychiatry, 7.

La Greca, A. M., Silverman, W. K., Vernberg, E. M., \& Prinstein, M. J. (1996). Symptoms of posttraumatic stress in children after Hurricane Andrew: A prospective study. Journal of Consulting and Clinical Psychology, 64, 712-23.

Lack, C. W., \& Sullivan, M. A. (2007). Attributions, coping, and exposure as predictors of longterm posttraumatic distress in tornado-exposed children. Journal of Loss and Trauma, 13, $72-84$.

Marsac, M. L., Kassam-Adams, N., Delahanty, D. L., Ciesla, J., Weiss, D., Widaman, K. F., \& Barakat, L. P. (2017). An initial application of a biopsychosocial framework to predict posttraumatic stress following pediatric injury. Health Psychology, 36, 787-96. 
McDermott, B. M., Lee, E. M., Judd, M., \& Gibbon, P. (2005). Posttraumatic stress disorder and general psychopathology in children and adolescents following a wildfire disaster. The Canadian Journal of Psychiatry, 50, 137-43.

McDermott Sales, J., Fivush, R., Parker, J., \& Bahrick, L. (2005). Stressing memory: Long-term relations among children's stress, recall and psychological outcome following Hurricane Andrew. Journal of Cognition and Development, 6, 529-45.

Meiser-Stedman, R., Dalgleish, T., Glucksman, E., Yule, W., \& Smith, P. (2009). Maladaptive cognitive appraisals mediate the evolution of posttraumatic stress reactions: A 6-month follow-up of child and adolescent assault and motor vehicle accident survivors. J Abnorm Psychol, 118, 778-87.

Pfefferbaum, B., North, C. S., Doughty, D. E., Gurwitch, R. H., Fullerton, C. S., \& Kyula, J. (2003). Posttraumatic stress and functional impairment in Kenyan children following the 1998 American embassy bombing. American Journal of Orthopsychiatry, 73, 133-40.

Pfefferbaum, B. C., Doughty, D. E., Reddy, C., Patel, N., Gurwitch, R. H., Nixon, S. J., \& Tivis, R. D. (2002). Exposure and peritraumatic response as predictors of posttraumatic stress in children following the 1995 Oklahoma City bombing. Journal of Urban Health: Bulletin of the New York Academy of Medicine, 79, 354-63.

Stallard, P., Velleman, R., \& Baldwin, S. (1998). Prospective study of post-traumatic stress disorder in children involved in road traffic accidents. BMJ, 317, 1619-23.

Thienkrua, W., Cardozo, B. L., Chakkraband, M. L. S., Guadamuz, T. E., Pengjuntr, W., Tantipiwatanaskul, P., Sakornsatian, S., Ekassawin, S., Panyayong, B., Varangrat, A., Tappero, J. W., Schreiber, M., \& van Griensven, F. (2006). Symptoms of posttraumatic stress disorder and depression among children in tsunami-affected areas in Southern Thailand. JAMA: Journal of the American Medical Association, 296, 549-59. 
Winston, F. K., Kassam-Adams, N., García-España, J. F., Ittenbach, R. F., \& Cnaan, A. (2003). Screening for risk of persistent posttraumatic stress in injured children and their parents. Journal of the American Medical Association, 290, 643-49.

Zhou, P., Zhang, Y., Wei, C., Liu, Z., \& Hannak, W. (2016). Acute stress disorder as a predictor of posttraumatic stress: A longitudinal study of Chinese children exposed to the Lushan earthquake. Psych J, 5, 206-14. 
Supplementary Material 3. Description of how peritraumatic factors were assessed, with effect sizes extracted from each study.

\begin{tabular}{|c|c|c|c|c|}
\hline $\begin{array}{l}\text { Peritraumatic } \\
\text { factor }\end{array}$ & Study & Description of measure & $\mathbf{k}$ & Mean $\mathbf{r}$ \\
\hline \multicolumn{5}{|c|}{ 'A2' criteria; including fear, horror, helplessness or perceived life threat (PLT) } \\
\hline Fear & $\begin{array}{l}\text { Aaron, et al. } \\
\text { (1999) }\end{array}$ & $\begin{array}{l}\text { Narrative account from the child about the } \\
\text { event, their feelings during and } \\
\text { immediately after, and Likert scale } \\
\text { questions addressing level of fear and } \\
\text { perceived life threat. Index of overall fear } \\
\text { was created by summing the scores from } \\
\text { their self-reported fear and life threat } \\
\text { items. }\end{array}$ & 1 & 0.56 \\
\hline Fear & $\begin{array}{l}\text { Evans \& } \\
\text { Oehler-Stinnett } \\
\text { (2006) }\end{array}$ & $\begin{array}{l}\text { Self-report item rating how scared they felt } \\
\text { during the tornado }\end{array}$ & 1 & 0.42 \\
\hline Fear & $\begin{array}{l}\text { Filkuková, et } \\
\text { al. (2016) }\end{array}$ & $\begin{array}{l}\text { Semi-structured interview of trauma } \\
\text { experience; IPA to ascertain themes, } \\
\text { including fear during and immediately } \\
\text { after the attack }\end{array}$ & 1 & 0.24 \\
\hline Fear & $\begin{array}{l}\text { Lack \& } \\
\text { Sullivan } \\
\text { (2007) }\end{array}$ & $\begin{array}{l}\text { One item scale: } 5 \text { responses from not at all } \\
\text { scared to terrified }\end{array}$ & 1 & 0.48 \\
\hline Fear & $\begin{array}{l}\text { McDermott } \\
\text { Sales, et al. } \\
(2005)\end{array}$ & $\begin{array}{l}\text { Child rated how scared, upset or frightened } \\
\text { or relaxed and happy they felt during the } \\
\text { event, by indicating which of two puppets } \\
\text { (frightened vs relaxed) they felt like, and } \\
\text { then asked to indicate how much they felt } \\
\text { like that ( } 1 \text { to } 4 \text { response scale from } \\
\text { extremely happy and good to extremely } \\
\text { frightened and upset). }\end{array}$ & 1 & 0.21 \\
\hline Fear & $\begin{array}{l}\text { Zhou, et al. } \\
\text { (2016) }\end{array}$ & $\begin{array}{l}\text { One item from a self-report questionnaire } \\
\text { assessing trauma experiences: 'Did you } \\
\text { feel scared when the earthquake } \\
\text { happened?' }\end{array}$ & 1 & 0.19 \\
\hline Fear \& PLT & $\begin{array}{l}\text { Ehlers, et al. } \\
\text { (2003) }\end{array}$ & $\begin{array}{l}\text { Child indicated whether they thought they } \\
\text { were going to get hurt or die, and the } \\
\text { extent to which they felt scared/frightened } \\
\text { during the event (scale } 1 \text { 'not scared' to } 3 \text { 'a } \\
\text { lot'); fear response score was the maximum } \\
\text { of these two answers. }\end{array}$ & 1 & 0.37 \\
\hline Fear \& PLT & $\begin{array}{l}\text { Kar, et al. } \\
(2007)\end{array}$ & $\begin{array}{l}\text { Unclear: "(child)... had extreme degree of } \\
\text { fear with perceived life threat during the } \\
\text { cyclone" }\end{array}$ & 1 & 0 \\
\hline Fear \& PLT & $\begin{array}{l}\text { Meiser- } \\
\text { Stedman, et al. } \\
(2009)\end{array}$ & $\begin{array}{l}3 \text { item measure including perceived life } \\
\text { threat, perceived threat of harm and feeling } \\
\text { scared }\end{array}$ & 1 & 0.48 \\
\hline Fear \& PLT & $\begin{array}{l}\text { Stallard \& } \\
\text { Smith }(2007)\end{array}$ & $\begin{array}{l}\text { Average score of three questions 'How } \\
\text { serious was your accident?', 'Did you }\end{array}$ & 1 & 0.58 \\
\hline
\end{tabular}


think that you were going to get hurt/die

during the accident', and 'Did you feel

frightened/scared during the accident?'

\begin{tabular}{|c|c|c|c|c|}
\hline Fear \& PLT & $\begin{array}{l}\text { Winston, et al. } \\
\text { (2003) }\end{array}$ & $\begin{array}{l}\text { STEPP questionnaire items 'when you got } \\
\text { hurt, or right afterwards, did you feel really } \\
\text { afraid?' and 'when you got hurt, or right } \\
\text { afterwards, did you think you might die?' }\end{array}$ & 2 & 0.25 \\
\hline PLT & $\begin{array}{l}\text { Duffy, et al. } \\
\text { (2015) }\end{array}$ & $\begin{array}{l}\text { Unclear- possibly two items from 10-item } \\
\text { exposure questionnaire rating whether the } \\
\text { person 'thought he/she was going to die' } \\
\text { and if they 'saw others who they thought } \\
\text { were going to die'. }\end{array}$ & 2 & 0.31 \\
\hline PLT & $\begin{array}{l}\text { La Greca, et al. } \\
\text { (1996) }\end{array}$ & $\begin{array}{l}\text { One item from hurricane-related traumatic } \\
\text { experiences (HURTE) scale: 'at any point } \\
\text { during the hurricane, did you think you } \\
\text { might die?' }\end{array}$ & 1 & 0.29 \\
\hline PLT & $\begin{array}{l}\text { McDermott, et } \\
\text { al. (2005) }\end{array}$ & $\begin{array}{l}\text { Unclear- possibly two items from a } \\
\text { wildfires experiences questionnaire } \\
\text { 'thought I might die' and 'thought family } \\
\text { member might die' }\end{array}$ & 2 & 0.47 \\
\hline PLT & $\begin{array}{l}\text { Nordanger, et } \\
\text { al. (2014) }\end{array}$ & $\begin{array}{l}\text { One item measure: 'To what extent did you } \\
\text { perceive the terror events as a threat to } \\
\text { your own life or the lives of someone close } \\
\text { to you?' }\end{array}$ & 1 & 0.38 \\
\hline PLT & $\begin{array}{l}\text { Polusny, et al. } \\
\text { (2011) }\end{array}$ & $\begin{array}{l}\text { Sum of three items from HURTE } \\
\text { (Hurricane-Related Traumatic } \\
\text { Experiences) questionnaire; 'did you get } \\
\text { hurt in the storm?', 'were you afraid you } \\
\text { would be injured in the storm?' and 'were } \\
\text { you afraid you would be killed in the } \\
\text { storm?' (with few endorsing sustaining } \\
\text { injury, so predominantly a measure of } \\
\text { perceived threat of harm or life threat). }\end{array}$ & 1 & 0.5 \\
\hline PLT & $\begin{array}{l}\text { Stallard, et al. } \\
\text { (1998) }\end{array}$ & $\begin{array}{l}\text { Semi-structured interview asking children } \\
\text { to describe what happened during and } \\
\text { immediately after the event. Reported as } \\
\text { 'thought I would die'. }\end{array}$ & 1 & 0.39 \\
\hline $\begin{array}{l}\text { Terror, } \\
\text { helplessness, } \\
\text { PLT \& fear }\end{array}$ & $\begin{array}{l}\text { Bödvarsdóttir, } \\
\text { et al. (2006) }\end{array}$ & $\begin{array}{l}\text { Questionnaire about stressors during the } \\
\text { earthquake: one item assessing fear of } \\
\text { death; one item assessing feelings of terror; } \\
\text { and one item assessing helplessness felt } \\
\text { during the earthquake. }\end{array}$ & 3 & 0.4 \\
\hline PLT \& distress & $\begin{array}{l}\text { Giannopoulou, } \\
\text { et al. (2006) }\end{array}$ & $\begin{array}{l}\text { Index of perceived life threat: sum of } \\
\text { endorsed items including fear of death, } \\
\text { concern for the safety of others. Index of } \\
\text { distress: sum of endorsed items including } \\
\text { distress at witnessing scenes in the } \\
\text { neighbourhood and distress at viewing } \\
\text { scenes on TV. }\end{array}$ & 2 & 0.29 \\
\hline $\begin{array}{l}\text { Fear, PLT \& } \\
\text { helplessness }\end{array}$ & $\begin{array}{l}\text { Holmes, et al. } \\
\text { (2007) }\end{array}$ & $\begin{array}{l}\text { Self-report items: 'when you saw the } \\
\text { attack did you feel scared?', 'did you feel }\end{array}$ & 3 & 0.36 \\
\hline
\end{tabular}




\begin{tabular}{|c|c|c|c|c|}
\hline & & $\begin{array}{l}\text { like your life was in danger?' and 'did you } \\
\text { feel like there was nothing you could do?' }\end{array}$ & & \\
\hline $\begin{array}{l}\text { Fear, PLT \& } \\
\text { helplessness }\end{array}$ & $\begin{array}{l}\text { Thienkrua, et } \\
\text { al. (2006) }\end{array}$ & $\begin{array}{l}\text { Tsunami modified version of the 'PsyStart } \\
\text { Rapid triage system' used to ask questions } \\
\text { about trauma experiences: 'felt one's own } \\
\text { or a family members life in danger', 'felt } \\
\text { unable to escape', and 'felt extreme panic } \\
\text { or fear'. }\end{array}$ & 3 & 0.21 \\
\hline Distress & $\begin{array}{l}\text { Bui, et al. } \\
\text { (2011) }\end{array}$ & $\begin{array}{l}\text { Peritraumatic Distress Inventory: } 13 \text { self- } \\
\text { report items assessing the A } 2 \text { criteria of } \\
\text { DSM-IV PTSD, including: criteria } \\
\text { sadness/grief, frustrated/angry, afraid for } \\
\text { own safety, guilt, ashamed of emotional } \\
\text { reaction, worried for the safety of others, } \\
\text { afraid of losing control of emotions, } \\
\text { difficulty controlling bladder, horror, } \\
\text { physical symptoms of panic, fear of } \\
\text { passing out, and perceived life threat. }\end{array}$ & 2 & 0.51 \\
\hline Distress & $\begin{array}{l}\text { Cénat \& } \\
\text { Derivois } \\
\text { (2015) }\end{array}$ & $\begin{array}{l}\text { Peri-traumatic distress inventory, as } \\
\text { described above. }\end{array}$ & 1 & 0.57 \\
\hline $\mathrm{A} 2$ & $\begin{array}{l}\text { Elklit \& } \\
\text { Kurdahl } \\
(2013)\end{array}$ & $\begin{array}{l}\text { Initial response to the event involving fear, } \\
\text { helplessness, horror or perceived life } \\
\text { threat. }\end{array}$ & 1 & 0.57 \\
\hline A 2 & $\begin{array}{l}\text { Lavi, et al. } \\
\text { (2013) }\end{array}$ & $\begin{array}{l}\text { Sense of fear during the war assessed by } \\
\text { five statements in accordance with the A2 } \\
\text { criteria for PTSD e.g. 'During the war I } \\
\text { felt that my life was in danger' }\end{array}$ & 1 & 0.59 \\
\hline A2 & $\begin{array}{l}\text { Marsac, et al. } \\
(2017)\end{array}$ & $\begin{array}{l}\text { Trauma-related appraisals: from ASC-Kids } \\
\text { peri-trauma } 4 \text { item subscale ('it was } \\
\text { shocking/awful horrible'; 'wanted to make } \\
\text { it stop but couldn't'; 'felt scared'; 'thought } \\
\text { might die') }\end{array}$ & 1 & 0.05 \\
\hline $\begin{array}{l}\text { Peritraumatic } \\
\text { response }\end{array}$ & $\begin{array}{l}\text { Pfefferbaum, } \\
\text { et al. (2002) }\end{array}$ & $\begin{array}{l}\text { 'Peri-traumatic response scale'; included } \\
12 \text { items addressing peritraumatic } \\
\text { responses of fear, arousal and dissociation: } \\
\text { 'thought I would die; trembling/shaking; } \\
\text { heart beat fast; nervous or afraid; made me } \\
\text { jump; on automatic pilot; scared someone } \\
\text { in my family would be hurt; scared a } \\
\text { friend/a teacher would be hurt; frightened } \\
\text { by how scared my teachers acted; upset by } \\
\text { how I acted; helpless.' Total score } \\
\text { indicating greater peritraumatic response. }\end{array}$ & 1 & 0.26 \\
\hline $\begin{array}{l}\text { Peritraumatic } \\
\text { response }\end{array}$ & $\begin{array}{l}\text { Pfefferbaum, } \\
\text { et al. (2003) }\end{array}$ & $\begin{array}{l}\text { 'Peritraumatic reaction scale', described as } \\
\text { above; } 13 \text { items on how the child felt when } \\
\text { the bomb went off. }\end{array}$ & 1 & 0.23 \\
\hline \multicolumn{5}{|c|}{ Peritraumatic dissociation } \\
\hline & $\begin{array}{l}\text { Brown, et al. } \\
(2016)\end{array}$ & $\begin{array}{l}\text { Peritraumatic dissociation items from the } \\
\text { DICA-ASD summed to create a } \\
\text { continuous dissociation total score }\end{array}$ & 1 & 0.2 \\
\hline
\end{tabular}




\begin{tabular}{|c|c|c|c|}
\hline $\begin{array}{l}\text { Bui, et al. } \\
\text { (2011) }\end{array}$ & $\begin{array}{l}\text { Peritraumatic dissociative experiences } \\
\text { questionnaire; } 10 \text { item questionnaire with } \\
\text { items describing dissociative experiences }\end{array}$ & 1 & 0.25 \\
\hline $\begin{array}{l}\text { Holmes, et al. } \\
(2007)\end{array}$ & $\begin{array}{l}\text { One item self-report: 'did it feel like it } \\
\text { wasn't real?' }\end{array}$ & 1 & 0 \\
\hline $\begin{array}{l}\text { Schäfer, et al. } \\
\text { (2004) }\end{array}$ & $\begin{array}{l}\text { Peritraumatic dissociation: children rated } \\
\text { the presence of each of the symptoms in } \\
\text { ASD criteria with the following items: } \\
\text { 'Did the world around you seem strange or } \\
\text { unreal?'; 'Did your body feel strange, as if } \\
\text { it was not really yours?'; 'Have you been } \\
\text { less aware of what was happening?'; 'Did } \\
\text { you feel numb or did you have no feelings } \\
\text { at all?'; 'Are there any important details } \\
\text { which you cannot remember?'. }\end{array}$ & 1 & 0.41 \\
\hline $\begin{array}{l}\text { Zatzick, et al. } \\
(2006)\end{array}$ & $\begin{array}{l}\text { Unclear- no description of how this was } \\
\text { assessed }\end{array}$ & 1 & 0 \\
\hline \multicolumn{4}{|l|}{ Data-driven processing } \\
\hline $\begin{array}{l}\text { Ehlers, et al. } \\
(2003)\end{array}$ & $\begin{array}{l}\text { One item question indicating the extent to } \\
\text { which they were muddled/confused during } \\
\text { the accident }\end{array}$ & 1 & 0.3 \\
\hline $\begin{array}{l}\text { Stallard \& } \\
\text { Smith (2007) }\end{array}$ & $\begin{array}{l}\text { One item 'Did you feel confused or } \\
\text { muddled during the accident?' }\end{array}$ & 1 & 0.28 \\
\hline
\end{tabular}




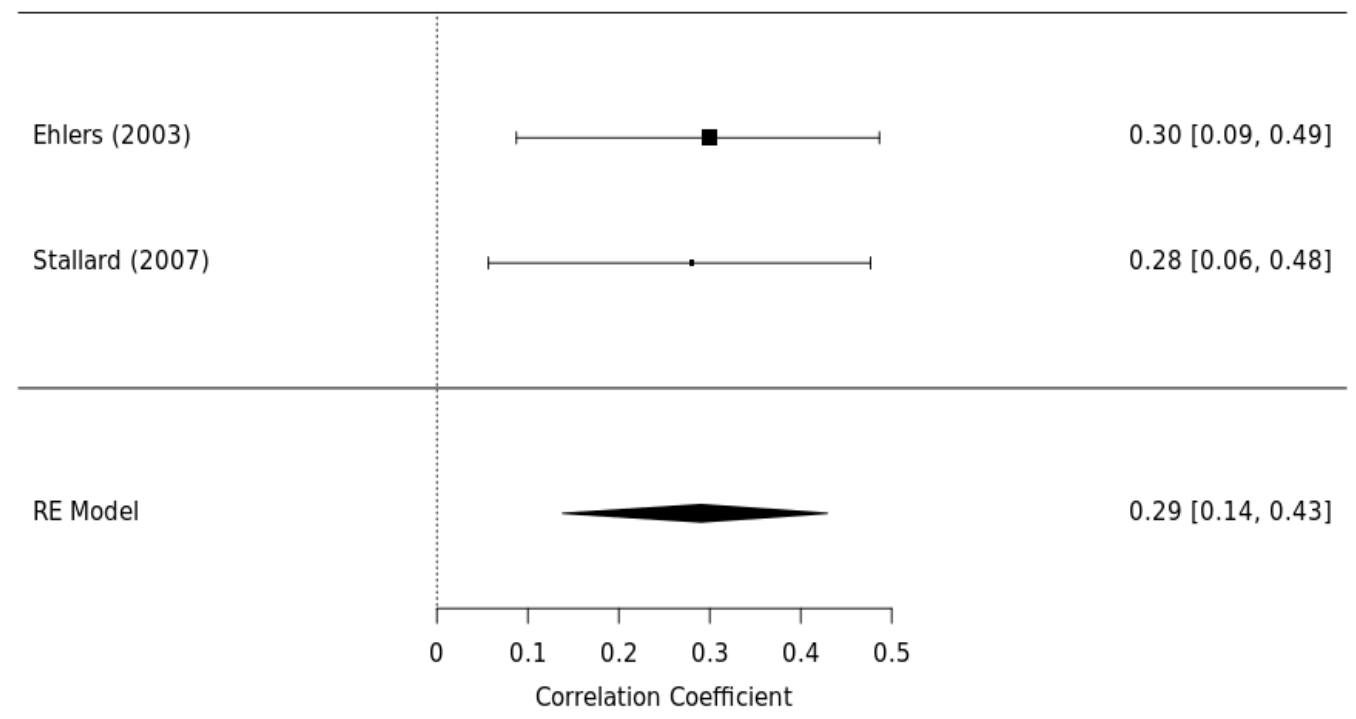

Supplementary Figure 1. Forest plot for meta-analysis of data-driven processing. Illustrating effect sizes (r) and the overall estimate of the effect size for the relationship between data-driven processing and PTSD symptoms in children and adolescents. 